\title{
Production of a functional cell wall-anchored minicellulosome by recombinant Clostridium acetobutylicum ATCC 824
}

\author{
Benjamin J. Willson ${ }^{1}$, Katalin Kovács ${ }^{1}$, Tom Wilding-Steele ${ }^{1}$, Robert Markus ${ }^{2}$, Klaus Winzer ${ }^{1}$ and Nigel P. Minton ${ }^{1 *}$
}

\begin{abstract}
Background: The use of fossil fuels is no longer tenable. Not only are they a finite resource, their use is damaging the environment through pollution and global warming. Alternative, environmentally friendly, renewable sources of chemicals and fuels are required. To date, the focus has been on using lignocellulose as a feedstock for microbial fermentation. However, its recalcitrance to deconstruction is making the development of economic processes extremely challenging. One solution is the generation of an organism suitable for use in consolidated bioprocessing (CBP), i.e. one able to both hydrolyse lignocellulose and ferment the released sugars, and this represents an important goal for synthetic biology. We aim to use synthetic biology to develop the solventogenic bacterium C. acetobutylicum as a CBP organism through the introduction of a cellulosome, a complex of cellulolytic enzymes bound to a scaffold protein called a scaffoldin. In previous work, we were able to demonstrate the in vivo production of a $C$. thermocellum-derived minicellulosome by recombinant strains of C. acetobutylicum, and aim to develop on this success, addressing potential issues with the previous strategy.

Results: The genes for the cellulosomal enzymes Cel9G, Cel48F, and Xyn10A from C. cellulolyticum were integrated into the C. acetobutylicum genome using Allele-Coupled Exchange (ACE) technology, along with a miniscaffoldin derived from C. cellulolyticum CipC. The possibility of anchoring the recombinant cellulosome to the cell surface using the native sortase system was assessed, and the cellulolytic properties of the recombinant strains were assayed via plate growth, batch fermentation and sugar release assays.

Conclusions: We have been able to demonstrate the synthesis and in vivo assembly of a four-component minicellulosome by recombinant C. acetobutylicum strains. Furthermore, we have been able to anchor a minicellulosome to the C. acetobutylicum cell wall by the use of the native sortase system. The recombinant strains display an improved growth phenotype on xylan and an increase in released reducing sugar from several substrates including untreated powdered wheat straw. This constitutes an important milestone towards the development of a truly cellulolytic strain suitable for CBP.
\end{abstract}

Keywords: Cellulosome, Scaffoldin, Sortase anchoring, Consolidated bioprocessing, Clostridium acetobutylicum

\section{Background}

In recent years, biofuels such as bioethanol have received increasing attention as potential alternatives to fossil fuels. However, the use of 'first generation' biofuels, i.e.

\footnotetext{
*Correspondence: nigel.minton@nottingham.ac.uk

${ }^{1}$ Clostridia Research Group, BBSRC/EPSRC Synthetic Biology Research Centre, School of Life Sciences, University of Nottingham, Nottingham NG7 2RD, UK

Full list of author information is available at the end of the article
}

those produced using food crop-derived sugars as feedstock, is not without its issues. The use of food stocks may lead to elevated prices as a result of increased demand, while the use of limited water resources and agricultural land will reduce the land available for food production $[1,2]$. More attractive would be to use lignocellulosic biomass, a complex material which makes up the cell walls of plants [3]. Lignocellulose consists primarily of cellulose, a $\beta 1$, 4-linked polymer of glucose; other 
components are hemicelluloses, branched polymers of xylose, glucose, and/or mannose [4], and lignin, a polymer of aromatic alcohols [5]. As a feedstock for microbial fermentations, the most readily available sources of biomass include agricultural and domestic wastes as well as dedicated crops such as willow and switchgrass [6]. However, lignocellulose is notoriously recalcitrant to deconstruction. Its exploitation is reliant on an energy intensive pre-treatment step [7] and, thereafter, the addition of costly exogenous hydrolytic enzymes required to convert the partially deconstructed biomass into the sugars needed by the fermentative process organisms. The costs involved are making the development of economic processes extremely challenging.

To improve process economics, the concept of consolidated bioprocessing (CBP) has been proposed, where a single organism or consortium is able to both degrade lignocellulose and ferment all the released sugars [8]. As no suitable organism has been isolated from nature, the generation of a CBP organism presents a challenging goal for synthetic biology.

At present, efforts to develop an organism for CBP fall into two categories [8]. In the 'native' strategy, an organism that is able to efficiently degrade lignocellulose is engineered for biofuel production. This can involve the improvement of the characteristics or yield of a native solvent producer such as Clostridium thermocellum [9] (Ruminiclostridium thermocellum [10]) or the introduction of new metabolic pathways into a non-solventogenic organism such as Clostridium cellulovorans [11]. Conversely, the 'recombinant' strategy involves the engineering of well-established solvent producers to use lignocellulose as a feedstock through the expression of cellulolytic enzymes. Several studies so far have focused on the ethanol-producing yeast Saccharomyces cerevisiae $[12,13]$. Nevertheless, the recent retraction of an article purporting to show the development of a strain of Bacillus subtilis able to grow on lignocellulosic biomass highlights the challenges of engineering organisms for CBP [14].

One organism that is of particular interest as a potential CBP chassis is Clostridium acetobutylicum, a Grampositive, spore forming, obligate anaerobe that belongs to the group I clostridia $[15,16]$. C. acetobutylicum is able to rapidly convert sugars into solvents through the acetone-butanol-ethanol (ABE) fermentation pathway. It was formerly used from the First World War onwards on an industrial scale, initially to produce acetone and subsequently for the production of butanol. By the middle of the last century, however, the price of feedstocks made the $\mathrm{ABE}$ process uneconomic compared to the production of butanol by the petrochemical industry, resulting in the closure of $\mathrm{ABE}$ plants [17]. In recent times, interest in butanol has intensified due to its superior properties as a biofuel compared to ethanol [18]. This has provided the impetus to reappraise the benefits of the ABE process. $C$. acetobutylicum, while unable to natively utilise lignocellulose, is able to utilise all the hexose and pentose sugars that result from its deconstruction [19]. By engineering cellulolytic activity into C. acetobutylicum, it may be possible to create a strain that is capable of fermenting lignocellulosic material, making butanol production through ABE fermentation both sustainable and cost effective.

In nature, lignocellulose is broken down by specialised organisms using one of two strategies [20]. The first involves the secretion of a wide variety of free cellulolytic enzymes into the environment, whereas the second is reliant on the production of a large extracellular complex called a cellulosome. In cellulosomal systems, enzymes are anchored to a scaffolding protein called a 'scaffoldin' as a result of interactions between the cohesin domains of the scaffoldin and the dockerin domains of the enzymes. In most cases, the incorporation into the scaffoldin of a carbohydrate binding module (CBM) with specificity for cellulose allows the complex to adhere to the substrate [21]. Cellulosomal systems are generally found in anaerobic bacteria and are hypothesised to be an adaptation to the limitations of an anaerobic environment; the assembly of the enzymes into a complex allows greater synergy between enzymes with different activities, potentially reduces the competition for binding sites on the substrate, and allows the anchoring of the complex to the cell [22, 23]. Interestingly, C. acetobutylicum is able to produce a cellulosome [24], although it appears to be inactive.

The potential of C. acetobutylicum for CBP has not gone unnoticed and, to date, a number of studies have focused on the heterologous expression of cellulases and cellulosomal components with this organism. However, expression of many of these components has proven difficult. While miniscaffoldins $[25,26]$ and several cellulosomal enzymes [26-28] have been successfully overexpressed, certain enzymes, such as Cel9G, Cel48F and Cel9E from Clostridium cellulolyticum (Ruminiclostridium cellulolyticum [10]), have been shown to be detrimental when their genes are overexpressed on multicopy plasmid vectors. Nevertheless, in our previous work [29], we were able to successfully demonstrate the production of a number of cellulosomal enzymes, including Cel48S, a GH48 cellulase, from encoding genes that had been integrated into the $C$. acetobutylicum genome. While genomic integration of the genes appeared to resolve the toxicity issues associated with plasmid-based overexpression, the resulting strains were still unable to utilise lignocellulosic material. In this work, we aimed to address the potential issues that we had identified in our previous 
strategy, continuing the development of C. acetobutylicum as a CBP organism.

\section{Results and discussion}

Selection of cellulosomal components

Our previous work focused on the expression of cellulosomal genes sourced from a thermophile, C. thermocellum. Here, we chose to express cellulases from a mesophile, namely, C. cellulolyticum, as we suspected that enzymes from a mesophilic background may have a greater activity in cultures of $C$. acetobutylicum. We selected two glucanase enzymes for inclusion in our cellulosome constructs: Cel9G and Cel48F. Cel48F is a processive endocellulase [30] that is mainly active towards crystalline cellulose and is the most prevalent enzyme in C. cellulolyticum cellulosomes [31], whereas Cel9G is an endoglucanase [32], a major enzyme in C. cellulolyticum cellulosomes [31], and is mainly active towards soluble substrates such as CMC and glucan [33]. When in a complex with a cellulase such as Cel48F or Cel9E, Cel9G displays a very strong synergy against insoluble celluloses such as Avicel and bacterial cellulose [34]. Although Cel9G is not the most active C. cellulolyticum GH9 enzyme, the combination of Cel48F and Cel9G provides a higher rate of Avicel degradation than any other Cel48F/ GH9 combination [33]. One possible explanation for this synergy is the action of the Cel9G carbohydrate binding module, CBM3c. While this domain does not bind as strongly to cellulose as the CBM3a and 3b domains of cellulosomal scaffoldins [35], it may disrupt the structure of the cellulose, providing more opportunity for enzymatic attack [36].

To further improve the activity of the cellulosomes towards 'natural' substrates, we also chose to express a xylanase. The removal of xylan has been shown to be necessary for the efficient breakdown of lignocellulose by synthetic minicellulosomes [37]; while C. acetobutylicum ATCC 824 does express xylanases [38], it is only capable of efficient growth on xylan as a sole carbon source when in a $\mathrm{pH}$-controlled chemostat culture [39]. C. acetobutylicum is reportedly unable to grow on solid medium with xylan as a sole carbon source, and could only grow in batch culture if xylose was added to promote xylan metabolism [39]. We hypothesised that the native xylanases may not be efficiently expressed under the conditions that would be found in a potential fermentation of lignocellulose, and activity against lignocellulose may be more likely if a cellulosomal xylanase is constitutively expressed. For this purpose, we chose Xyn10A (Ccel_0931), a smaller enzyme consisting of only a GH10 domain and dockerin [40]. Xyn10A has been identified in C. cellulolyticum cellulosomes [31], albeit at a lesser level than Cel9G or Cel48F; while no direct experimental data are available for the activity of Xyn10A, it bears a high degree of homology to known endoxylanases such as XynB from Thermotoga maritima [40]. Interestingly, unlike other GH10 enzymes from $C$. cellulolyticum, Xyn10A appears to be upregulated when cells are grown in the presence of crystalline cellulose [41].

Previously [29], we expressed heterologous genes from synthetic operons integrated into the chromosome using Allele-Coupled Exchange (ACE) technology, with expression driven by the genomic $\mathrm{P}_{t h l}$ and additional $\mathrm{P}_{\mathrm{BB} 2 \text { thloID }}$ promoters. However, we observed that in the longer operon constructs, the expression levels of the downstream components were significantly reduced. To address this issue, we decided to express our components from individual promoters. At present, ACE has been exemplified at two different loci in $C$. acetobutylicum [42]: the pyrE locus and the $t h l$ locus. Genes integrated at the thl locus are under the transcriptional control of the native thiolase gene $(t h l)$ promoter, $\mathrm{P}_{t h l}$, whereas those integrated at the pyrE locus require the use of an additional promoter. In preliminary work, we were able to observe the in vivo formation of minicellulosomes (data not shown) from $C$. acetobutylicum strains with a miniCipC scaffoldin integrated at the $t h l$ locus and with either Cel9G or Cel48F integrated at the pyrE locus under the control of the $\mathrm{P}_{\text {facoID }}$ promoter (comprising the promoter of the Clostridium pasteurianum ferredoxin gene into which was inserted a single ideal lac operator). Thus, we chose to expand upon this strategy by integrating the scaffoldin-encoding gene at the $t h l$ locus and a gene cassette encoding hydrolase enzymes at the pyrE locus.

\section{Assembly and expression of heterologous cellulosome components}

A mini-CipC3 scaffoldin gene cassette, encoding the CBM, $\mathrm{X}$ domain, and first three cohesin domains of $C$. cellulolyticum CipC, was assembled from separate BB2 fragments and integrated at the $t h l$ locus through $\mathrm{ACE}$ in the same manner as the mini-CipA scaffoldins in our previous work [29]. In preliminary experiments, production of this construct was compared to a scarless variant synthesised as a single BB2 fragment, and no difference was observed (data not shown). Thus, we decided to continue with the BB2-assembled variant. However, integration of the enzyme-encoding gene modules was more complicated. To prevent homologous recombination within our enzyme-encoding cassette, it was necessary to use a unique promoter for each gene module. Two promoters were already available: the $\mathrm{P}_{\mathrm{BB} 2 \text { thloID }}$ promoter (the BB2format C. acetobutylicum $\mathrm{P}_{\text {thl }}$ promoter containing a single ideal lac operator) used in our previous work [29], and the $\mathrm{P}_{\text {facoID }}$ promoter used in preliminary experiments. A BB2-format variant of the $\mathrm{P}_{f a c \text { Oid }}$ promoter, $\mathrm{P}_{\mathrm{BB} 2 f a c \mathrm{Oid}}$, was 
generated following the same principles as the $\mathrm{P}_{\mathrm{BB} 2 \text { thlOid }}$ promoter, incorporating the RBS from the C. acetobutylicum $\mathrm{P}_{\text {thl }}$ promoter. A third promoter, $\mathrm{P}_{-\mathrm{BB} 2 f d x \mathrm{OID}}$, was designed, consisting of the promoter of the C. sporogenes ferredoxin gene $(f d x)$ that incorporated a single ideal $l a c$ operator and $\mathrm{P}_{t h l} \mathrm{RBS}$. Of these three promoters, the $\mathrm{P}_{\mathrm{BB}-}$ $2 f a c \mathrm{OID}$ promoter was found to be the strongest, whereas the $\mathrm{P}_{\mathrm{BB} 2 \text { thlOID }}$ promoter was the weakest (data not shown). When the enzymes were expressed individually from the $\mathrm{P}_{\text {fac Oid }}$ promoter, we observed the Cel48F gene to exhibit the lowest expression level (Fig. 1). Thus, it was assigned the $\mathrm{P}_{\mathrm{BB} 2 f a c \text { OID }}$ promoter, in order to maximise the production of this important enzyme. As the Xyn10A gene had the highest level of expression, and was assumed to be of less overall importance, it was assigned the weaker $\mathrm{P}_{\mathrm{BB} 2 \text { thloID }}$ promoter. Thus, the Cel9G gene was assigned the intermediate-strength $\mathrm{P}_{\mathrm{BB} 2 f d x \mathrm{OID}}$ promoter.

To prevent possible interference between the promoters, we chose to place terminators between each gene. Due to the limited range of proven terminators in C. acetobutylicum, it was necessary to analyse a range of Rhoindependent terminators. The E. coli $r r n B$ T1 terminator and $B$. subtilis gyrA terminator were synthesised based on the existing sequences in the registry of standard

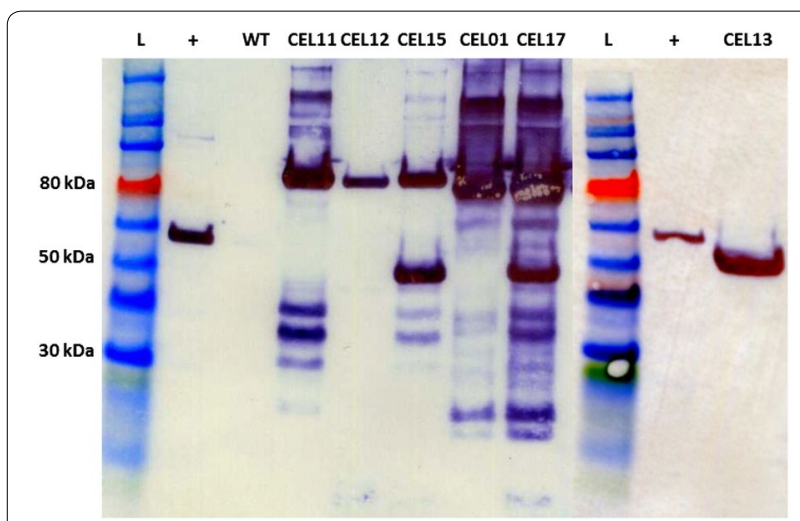

Fig. 1 SDS-PAGE/western blot analysis of supernatants from recombinant $C$. acetobutylicum strains producing heterologous cellulosome components encoded by chromosomally integrated gene constructs. Supernatants were obtained at an $\mathrm{OD}_{600}$ of approximately 0.8 and proteins concentrated 100-fold by TCA precipitation before being separated on 4-12\% Bis-Tris gradient gels. All cellulosomal components have been engineered to bear the FLAG epitope tag at the C-terminus, allowing visualisation using ANTI-

FLAG M2 monoclonal antibody-horseradish peroxidise conjugate. Supernatants were obtained from wild-type C. acetobutylicum (WT) and from strains CEL11, expressing a gene encoding Cel9G-FLAG, CEL12, expressing a gene encoding Cel48F-FLAG, CEL13, expressing a gene encoding Xyn10A-FLAG, CEL15, expressing genes encoding all three enzymes (Xyn10A-FLAG, Cel9G-FLAG, and Cel48F-FLAG), CEL01, expressing a gene encoding the BBCipC3-FLAG miniscaffoldin, and CEL17, expressing genes encoding all three enzymes and the BBCipC3-FLAG miniscaffoldin. L, ColorPlus Prestained Protein Ladder (10-230 kDa); +, carboxy terminal FLAG-BAP control protein (50 kDa) biological parts [43] (BBa_B0010 and BBa_K780000, respectively). Additional terminators were synthesised based on the terminators of the Lactococcus lactis pepN gene [44], the Lactobacillus acidophilus and Clostridium difficile (Peptoclostridium difficile [10]) slpA genes [45, 46], the B. subtilis $\Phi 29$ phage late TD1 transcript [47], and the B. subtilis tyrS tRNA gene [48]. The E. coli $r r n B$ T1 terminator, $\Phi 29$ TD1 terminator, $B$. subtilis tyrS terminator, and B. subtilis gyrA terminator had all been characterised in other organisms and found to give high levels of efficiency [47-50], whereas the L. lactis pepN and $L$. acidophilus $\operatorname{slp} A$ terminators had some evidence of activity [51,52]. After our own analysis of the efficacies of the terminators in C. acetobutylicum (Additional file 1: Figure S1), we selected the B. subtilis tyrS tRNA terminator (TtyrS) and E. coli rrnB T1 terminator (EcoT1) for subsequent use. The gene cassette was finally assembled in $C$. acetobutylicum with the organisational encod-

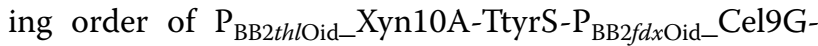

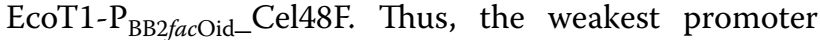
was placed before the first gene of the cassette, and the strongest at the end, so as to further minimise the effects of promoter interference.

While the use of $l a c$-repressible promoters enabled the assembly of single- or double-gene constructs in E. coli, it was not possible to assemble the triple-gene cassette as a single unit, as expression of Cel48F and Cel9G had a toxic effect. This is likely to result from an inability to secrete the proteins efficiently, potentially due to blockage of the secretion system; overexpression of Cel48F has been observed to result in accumulations of Cel48F as inclusion bodies in the cytoplasm and periplasm, of which around $50 \%$ had been processed by the secretion machinery but not exported [53]. Cel9G is also known to form inclusion bodies when produced in E. coli and may be subject to the same secretion defect [32].Plasmids carrying double-gene constructs were only successfully isolated after growth at $30{ }^{\circ} \mathrm{C}$ for 3 days on solid medium and for $48 \mathrm{~h}$ in liquid culture. Nevertheless, we were able to integrate the entire three-enzyme-encoding gene cassette into the genome in two consecutive steps through the use of iterative ACE [42]. The correct identity of the integrants was confirmed by nucleotide sequencing of appropriately amplified PCR products. The production of all three enzymes that would result from the integration of all three genes did not appear to have any significant negative impact on the growth phenotype of the strain.

Denaturing western blot analysis of the recombinant strains (Fig. 1) demonstrated that all the introduced cellulosome components can be produced and secreted by C. acetobutylicum. Although we have previously used the ACE technology to engineer C. acetobutylicum for production of cellulase enzymes [29], the enzymes chosen 
here have been previously established as being especially difficult to produce in C. acetobutylicum [27]. Thus, the expression of these enzymes provides a further exemplification of the utility of ACE technology for creating stable genomic insertions. Although Cel9G, Cel48F and CipC3 migrate at roughly the same speed, it is possible in the three-enzyme coexpression (XGF and XGF:C) samples to observe degradation products corresponding to each of the individual components: Cel9G produces degradation products migrating at roughly 35 and $40 \mathrm{kDa}$, Cel48F produces a roughly $5 \mathrm{kDa}$ degradation product, and CipC3 produces a $15 \mathrm{kDa}$ degradation product. It is important to note that expression levels of the components are not dependent solely on the strength of the promoter; when expressed from the $\mathrm{P}_{f a c \mathrm{OID}} / \mathrm{P}_{\mathrm{BB} 2 \mathrm{fac} O \mathrm{Oid}}$ promoter, the levels of Cel9G and Xyn10A produced are far greater than those of Cel48F. Using the weaker $\mathrm{P}_{\mathrm{BB} 2 f d x-}$ oID promoter for Cel9G, we reduced the level of Cel9G in the coexpression strain to more closely correspond to the level of Cel48F. However, the levels of Xyn10A produced in the coexpression strains are roughly equivalent to the levels of Cel9G and Cel48F combined, despite the use of the weaker $\mathrm{P}_{\mathrm{BB} 2 \text { thlOid }}$ promoter; when expressed alone from the $\mathrm{P}_{\mathrm{BB} 2 f a c \text { Oid }}$ promoter, the levels of Xyn10A appear to be even greater.

Native PAGE analysis (Fig. 2) revealed that the secreted components were capable of forming a cellulosome in vivo, visible as a large 'smear' pattern in the XGF:C sample. As no band corresponding to free Cel9G or Cel48F is visible, it is possible to infer that all the secreted enzymes are incorporated into cellulosomal complexes, and that the scaffoldin is in excess relative to the secreted enzymes. Interestingly, two 'smears' can be observed: one slowly migrating and indistinct, and one darker and more well defined. In preliminary work where only Cel9G and CipC3 were coexpressed, only the latter was observed (data not shown), suggesting that the indistinct 'smear' consists of complexes incorporating Xyn10A. This would be in agreement with the slower migration speed and less distinct band of uncomplexed Xyn10A. Interestingly, the 'smear' pattern observed for C. cellulolyticum-derived minicellulosomes does not resemble the defined banding patterns observed for C. thermocellum-derived complexes [29].

\section{Anchoring of scaffoldin to the cell wall}

In the natural environment, cellulosomes are typically anchored to the host cell. This allows the direct adherence of the cell to the substrate. As a result, the cell is able to remain in close proximity to the released sugars. Thus, when grown on cellulose in fast-flow culture, C. thermocellum has been observed to lose only 13.7-29.1\% of the released sugars into the medium [54]. Furthermore,

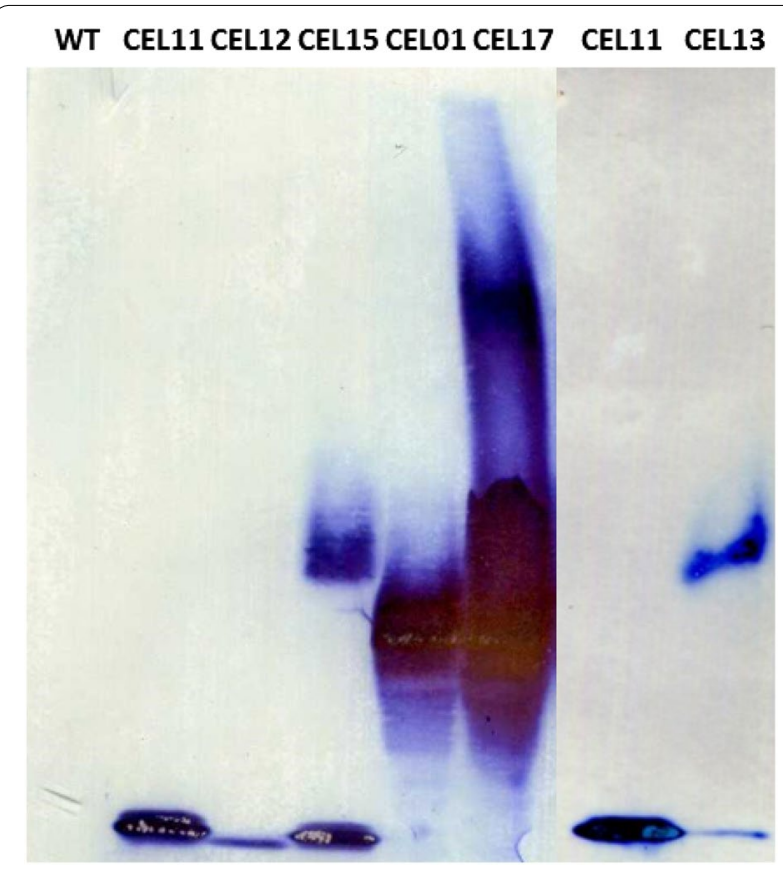

Fig. 2 Native PAGE/western blot analysis of supernatants from recombinant $C$. acetobutylicum strains producing heterologous, FLAG-tagged cellulosome components encoded by chromosomally integrated gene constructs. Supernatants were obtained at an $\mathrm{OD}_{600}$ of approximately 0.8 and proteins concentrated approximately 100-fold by ultrafiltration with a 10,000 MWCO filter before being separated on 3-8 \% Tris-Glycine gradient gels; after blotting, cellulosomal components were detected using ANTI-FLAG M2 monoclonal antibody-horseradish peroxidise conjugate. Supernatants were obtained from strains CEL11, expressing a gene encoding Cel9G-FLAG, CEL12, expressing a gene encoding Cel48F-FLAG, CEL13, expressing a gene encoding Xyn10A-FLAG, CEL15, expressing genes encoding all three enzymes (Xyn10A-FLAG, Cel9G-FLAG, and Cel48FFLAG), CEL01, expressing a gene encoding the BBCipC3-FLAG miniscaffoldin, and CEL17, expressing genes encoding all three enzymes and the BBCipC3-FLAG miniscaffoldin

by removing sugars from the immediate surroundings, the effect of product inhibition on the activity of the cellulases [55] is reduced. In nature, anchoring is accomplished through a variety of methods. 'Complex' cellulosomes, such as those of $C$. thermocellum, are able to anchor to the cell through a cohesin-dockerin interaction with a cell wall-anchored secondary scaffoldin [21]. For 'simple' cellulosomes, attachment has been observed through interaction with cell wall-anchored cellulase enzymes, as seen in C. cellulovorans [56], or through non-specific cell wall interactions, such as in C. cellulolyticum [57].

One interesting mechanism of cellulosome anchoring is found in certain Ruminococcus species, where the secondary scaffoldin is covalently attached to the cell wall via a sortase $[58,59]$. Sortases are a group of cysteine transpeptidases that are used by Gram-positive bacteria 
to covalently anchor proteins to the cell wall. The substrates are recognisable by the presence of a sortase signal sequence, consisting of a canonical LPXTG motif, hydrophobic region, and positively charged C-terminus [60]. The hydrophobic region and charged C-terminus lead to retention of the protein in the cell membrane, where it is cleaved by the sortase upon recognition of the LPXTG motif, forming an thioester intermediate; a nucleophilic attack from lipid II results in the formation of a lipid II-protein complex, which is integrated into the peptidoglycan [60].

The genome of $C$. acetobutylicum encodes a predicted sortase (CA_C0204) with four potential substrates [61]. As the use of the native sortase system would be a useful method for the anchoring of our own synthetic cellulosomes to the cell wall, we decided to examine the functionality of this system by appending the native sortase signals to our mini-CipC3 scaffoldin. Of the four potential substrates, we focused on an Icc-family phosphohydrolase (CA_C0205) and a cyclic AMP phosphorylase (CA_C0353). The other two proteins, an unclassified membrane protein and a SpoIID-like protein, were discounted. The membrane protein lacks an $\mathrm{N}$-terminal secretion signal and true LPXTG motif, having instead an LPKSG sequence, whereas the SpoIID-like protein has multiple LPXTG motifs throughout the protein, and a much shorter hydrophobic region [61].

As sortase signal sequences are located at the C-terminus of the target proteins, we wished to replicate the same arrangement within our mini-CipC constructs. Thus, it was necessary to generate a new mini-CipC3 variant without a C-terminal FLAG tag. In initial experiments, we designed a mini-CipC variant with an N-terminal FLAG tag, located immediately after the cleavage site of the CipC secretion signal peptide; however, this was found to affect the secretion of the protein (data not shown). As a result, we chose to locate the FLAG tag internally, in the linker region between the second and third cohesins, generating the $\mathrm{CipC} 2 \mathrm{~F} 3$ miniscaffoldin. Two variants, CipC2F3-CA_C0205ss and CipC2F3-CA_ C0353ss, carried the sortase signal sequences of the $C$. acetobutylicum Icc-family phosphohydrolase and cyclic AMP phosphorylase, respectively. All CipC-encoding variant genes were cloned into the pMTL-JH16 vector and integrated into the $C$. acetobutylicum genome at the $t h l$ locus, under the control of the genomic $\mathrm{P}_{t h l}$ promoter, in the same manner as the CipC3-FLAG construct described previously.

Strains expressing the different mini-CipC gene variants were subjected to cell fractionation (Fig. 3). The introduction of the FLAG tag between the second and third cohesin did not appear to have any effect on the distribution of $\mathrm{CipC}$ as compared to the original
C-terminally FLAG-tagged mini-CipC3. However, the introduction of the CA_C0353 and CA_C0205 sortase signal sequences resulted in small but detectable levels of CipC in the cell wall digest and cell fractions, suggesting that a small amount of CipC was being successfully anchored to the cell by the native sortase. To further confirm that this attachment was due to the presence of the sortase signal, we chose to co-express the $s r t A$ gene from Staphylococcus aureus, encoding a class A sortase (SaSrtA); $s r t A$ was introduced downstream of the CipC2F3CA_C0205ss scaffoldin gene, forming an operon under the control of the genomic $\mathrm{P}_{t h l}$ promoter. This sortase was chosen as it would be able to recognise the LPXTG motif found in the C. acetobutylicum sortase signals, but would be unable to subsequently attach the protein to the cell wall. Cell wall peptides are cross linked, and cell walls have been classified into different categories based on the structure of the cross link; S. aureus has a type A3a cell wall, with an interpeptide bridge consisting of five glycine residues, whereas $C$. acetobutylicum has been predicted to have a type A1y cell wall, where there is direct cross linking between a D-Ala residue of one peptide to an $\mathrm{m}$-Dpm residue of another [62]. The $S$. aureus sortase system anchors proteins to the pentaglycine bridge [63], which does not exist in C. acetobutylicum. As a result, while Sa-SrtA would be able to recognise and cleave the LPXTG motif, the protein would not be anchored to the cell wall, and would instead be released into the supernatant after nucleophilic attack from a water molecule [64]. Correspondingly, when Sa-SrtA and CipC2F3-CA C0205ss are co-produced, no signal can be observed in the cell wall and cell fractions, providing further evidence that the signal seen in the cell wall and cell fractions is a result of anchoring through the native sortase system.

\section{Effect of overexpressing the native sortase}

Although we were able to demonstrate some cell wall attachment, the amount of anchored $\mathrm{CipC}$ remained low compared to the amount in the supernatant. We hypothesised that the C. acetobutylicum sortase may either be only weakly active or poorly expressed, and that the high level of CipC3 expression was overwhelming the native system. Therefore, we decided to overproduce the native sortase (Ca-SrtA) by introducing a plasmid vector. To provide a comparison, we chose to express two other sortase genes, encoding the sortases from Bacillus cereus (Bc-SrtA) and Listeria monocytogenes (Lm-SrtA), respectively. Both organisms are predicted to share the same cell wall type as C. acetobutylicum [62] and both sortases recognise the same LPXTG motif $[65,66]$. The sortase of L. monocytogenes was chosen as it has been experimentally demonstrated to anchor proteins to the cross linking $\mathrm{m}$-Dpm residue [67], whereas the sortase of B. cereus was 


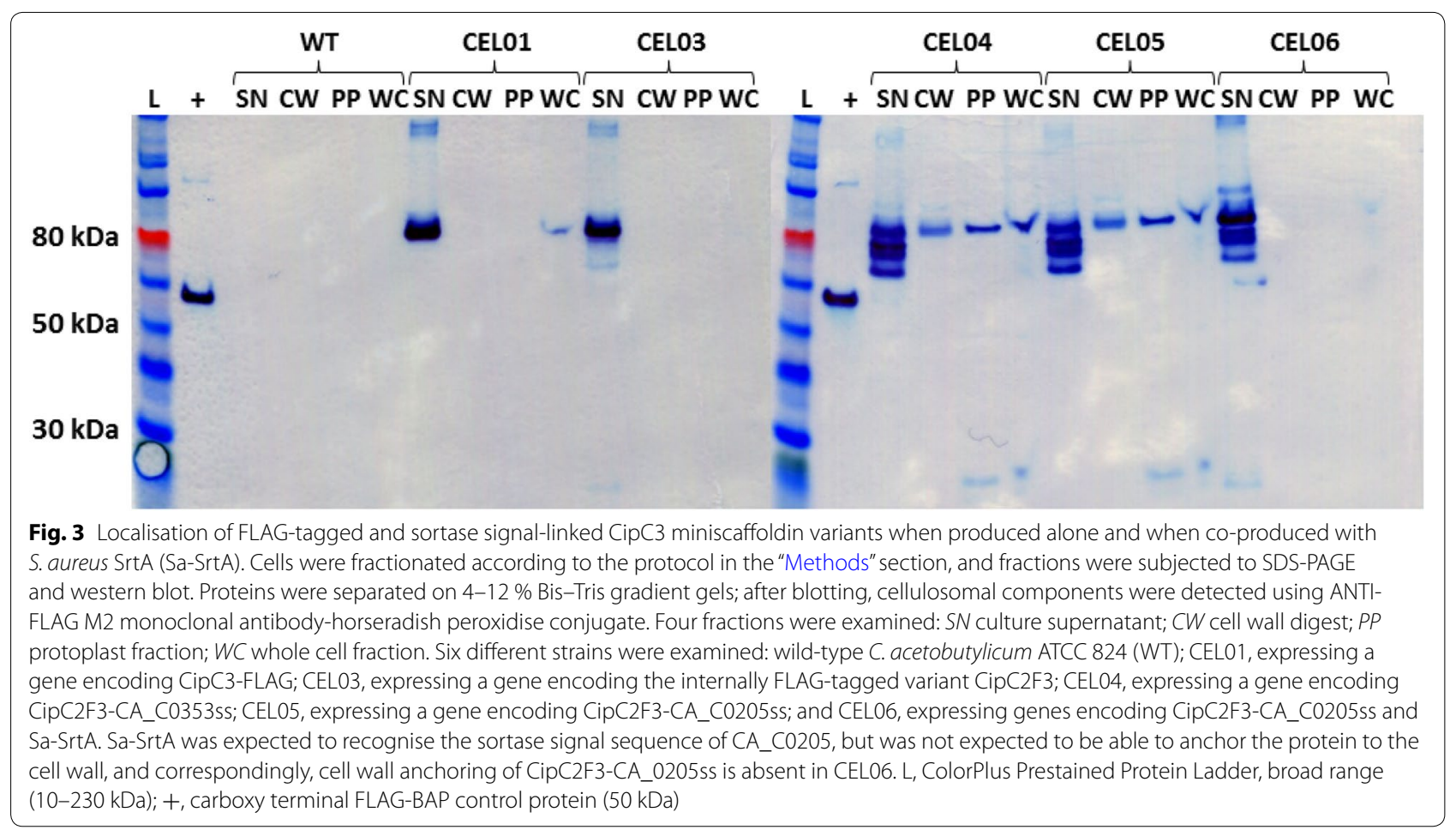

chosen due to its extremely high identity with the sortase of Bacillus anthracis, which had been recently used to anchor a synthetic miniscaffoldin to the cell wall of $B$. subtilis [14]. All three sortase genes were amplified from genomic DNA and cloned into the pMTL82151 shuttle vector under the control of the $\mathrm{P}_{\text {Tcpf }}$ promoter, comprising the $\mathrm{P}_{t h l}$ of $C$. perfringens with the RBS of the C. acetobutylicum $\mathrm{P}_{\text {thl }}$ promoter.

Combining production of CipC2F3-CA_C0205ss with overexpression of the native sortase gene resulted in an increase of CipC signal in the cell wall fraction (Fig. 4). With this level of protein, it is possible to see more clearly an additional band above the CipC band, potentially resulting from the presence of residual peptidoglycan fragments attached to the scaffoldin as has been seen with cell wall digests of $S$. aureus [68]. However, the signal in the cell fractions was significantly reduced. A likely explanation for this is that the signal in the cell fractions represents $\mathrm{CipC}$ that is anchored at the membrane, rather than on the cell wall; the protocol used for cell lysis would not hydrolyse significant amounts of peptidoglycan. Schneewind et al. [69] observed that when the LPXTG motif was removed from a fusion protein bearing a sortase signal, the localisation of that protein shifted from the cell wall to the membrane and cytoplasmic fractions. Accordingly, if the level of CipC production was sufficient to overwhelm the capacity of the native sortase system, we would expect a 'backlog' of unprocessed substrate to accumulate in these same fractions. When a sortase gene is overexpressed, this substrate can be processed, removing it from the membrane. Nevertheless, a significant amount of protein is lost to the supernatant, despite the overproduction of the sortase. Although the level of CipC in the wall fraction increases when the native sortase gene is overexpressed, this does not seem to be matched by a corresponding decrease in the full-length $\mathrm{CipC}$ in the supernatant, but by a decrease of the $75 \mathrm{kDa}$ degradation product. Thus, it is possible that a certain proportion of CipC is able to escape directly to the supernatant when being secreted, and that CipC is lost from the cell membrane due to the action of native proteases removing the $C$-terminal region before the protein can be processed by the sortase. Interestingly, while $C$. acetobutylicum, $B$. cereus and $L$. monocytogenes are predicted to have the same cell wall type, the expression of genes encoding Bc-SrtA and Lm-SrtA appears to reduce the level of cell wall anchoring, although they do not completely abolish anchoring in the same way as the $S$. aureus sortase. This may be a result of the cell wall structures of $C$. acetobutylicum, B. cereus and L. monocytogenes differing in ways other than the cross-linker residues; alternatively, the more acidic conditions of a $C$. acetobutylicum culture may be suboptimal for Bc-SrtA and Lm-SrtA activity.

While the majority of sortases have been shown to anchor proteins to the outside of the cell wall, there is a possibility that the $\mathrm{CipC}$ protein could be localised to 


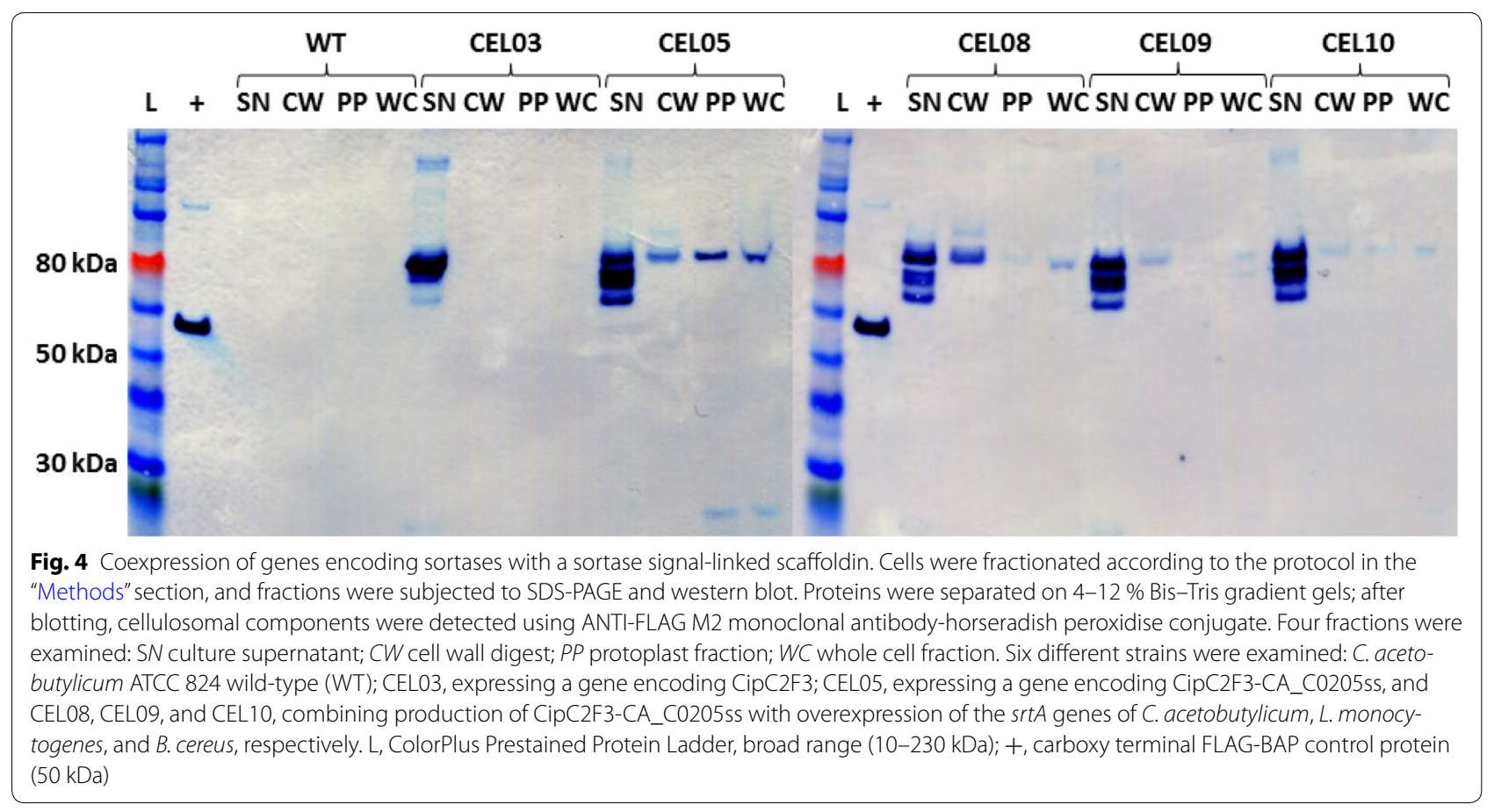

another region. Class $C$ sortases have been demonstrated to covalently join together multiple pilin subunits during pilus assembly, and in B. anthracis, a sortase substrate has been demonstrated to be anchored to the forespore by a class $\mathrm{D}$ sortase [60]. The sortase of $C$. acetobutylicum does not appear to fall into the classes described by Spirig et al. [60] and it is, therefore, difficult to predict the true role of $\mathrm{Ca}$-SrtA from sequence similarity alone. Furthermore, there is a possibility of that $\mathrm{CipC}$ is being mis-sorted. The replacement of the sortase signal of $S$. aureus protein A with other sortase signals can lead to mis-sorting even when a signal from the same organism is used [69]. Moreover, as $\mathrm{CipC}$ is not a native sortase substrate, then the potential for mis-sorting is likely to be even greater.

Although the results of the cell fractionation strongly suggest that CipC is being anchored to the cell wall, we sought further evidence through the use of fluorescence microscopy. The microscopy images obtained (Fig. 5) revealed a clear signal in cells producing the CipC2F3CA_C0205ss miniscaffoldin and Ca-SrtA sortase (Fig. 5b), whereas those only producing the sortase (Fig. 5a) only displayed a very small amount of background signal. As the secondary antibody is not monoclonal, it is likely that this small amount of background is a consequence of the animal source of the antibody already having antibodies that recognise C. acetobutylicum following prior exposure to a similar Clostridium species. The signal can be seen to be localised at the cell wall, providing evidence for the correct localisation of the scaffoldin. This conclusion is further supported by the observation that the signal appears to form a spiral around the outside of the cell (Fig. 5c), resembling the distribution of a sortase-anchored protein observed in $B$. subtilis [70].

\section{Assaying the cellulolytic potential of the strain}

Having demonstrated the expression of all heterologous cellulosome components, the in vivo assembly of the components into a complex, and the successful anchoring of a modified scaffoldin protein to the cell wall, we aimed to develop a strain capable of producing a functional, cell wall-anchored minicellulosome. Due to the use of both the thl and pyrE loci for strain construction, this was easily accomplished by the introduction of the CipC2F3-CA_C0205ss gene at the thl locus of C. acetobutylicum pyrE:XGF, followed by transformation with the pMTL82151_Tcpf_CaSrtA plasmid.

We then assayed the ability of the strains to grow on solid medium with only cellulosic substrates as a carbon source; the strains were streaked onto CBM-agar containing beechwood xylan, phosphoric acid-swollen cellulose (PASC), powdered wheat straw, or dilute acid pretreated willow bark. While no growth was observed on the cellulosic substrates (data not shown), a clear difference was visible when the recombinant strains were plated on xylan (Fig. 6). For the negative control strain, growth on xylan was only faintly visible after 7 days. 

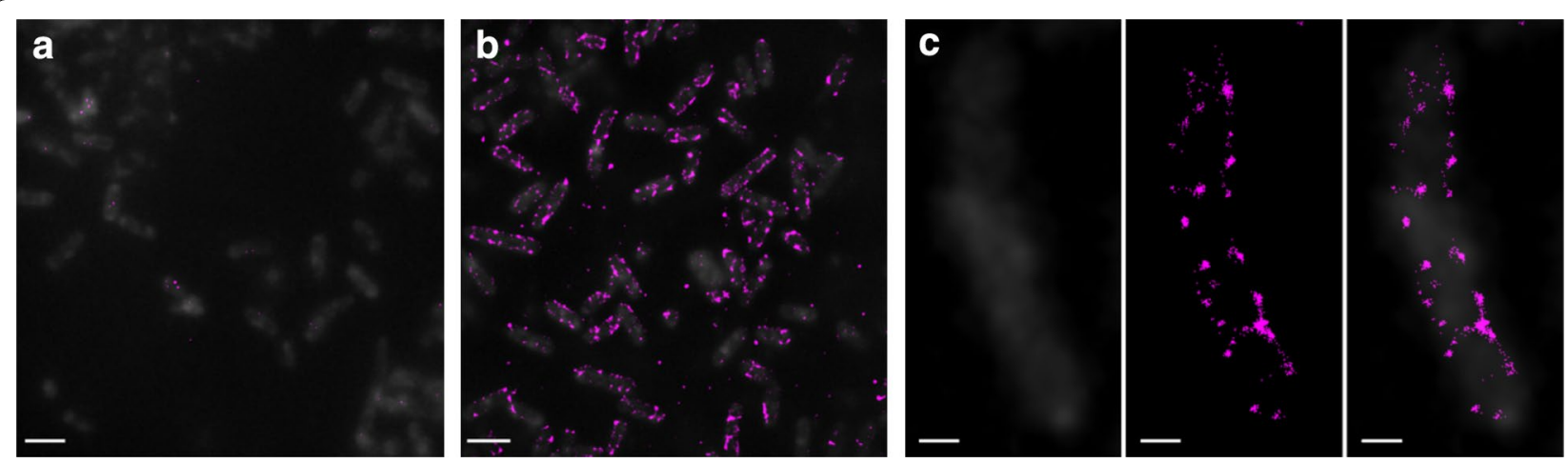

Fig. 5 Wide-field (grey) and dSTORM super resolution (magenta) fluorescent microscopy images of CipC-expressing C. acetobutylicum bacteria. The bacteria were visualised by their autofluorescence, detected in the green channel and shown here in grey; CipC was labelled by addition of anti-FLAG mouse monoclonal antibody followed by anti-mouse goat antibody conjugated to Alexa Fluor 647 dye and is shown as magenta pixels detected as single molecules in the far red channel. a Negative control (CEL07, overexpressing the native srtA gene) showing few background events, see the few pixels in magenta. b C. acetobutylicum CEL08 bacteria (producing CipC2F3-CA_0205ss and overexpressing the native srtA gene) displaying high number of $\mathrm{CipC}$ molecules on their surface. $\mathbf{c}$ Single CEL08 bacterium; the magenta pixels represent single molecule localisations of the labelled CipC. Scale bars a, b $2 \mu \mathrm{m}, \mathbf{c} 0.5 \mu \mathrm{m}$

However, for the strains expressing the hydrolase gene cassette, the rate of growth on xylan was largely similar to that on xylose, with growth appearing after 3 days and becoming well established at 5 days. This growth was accompanied by a visible zone of clearance, which is not apparent for the negative control even after 7 days of incubation. Interestingly, the colony phenotype of xylangrown $C$. acetobutylicum cultures was very different from that of those grown on xylose; colonies grown on xylose were pale, with little growth into the agar, and with single colonies emerging within the streak, whereas colonies grown on xylan were golden brown in colour and were firmly embedded into the agar. The strain CEL13, expressing Xyn10A only, was also discovered to grow on xylan plates, demonstrating that expression of Xyn10A was sufficient for growth (data not shown).

During the course of this work, we discovered that the laboratory strain of C. acetobutylicum ATCC 824 used (ATCC 824 COSMIC) contained a deletion of several genes located on the megaplasmid, including ptna, manYllevF, ptnd, CA_P0069, CA_P0070, and CA_P0071 [71]. As CA_P0071 is predicted to encode a xylanase, it was necessary to repeat the above experiment to compare the growth of the older strain with a newer strain re-acquired from the ATCC (November 2011). However, neither strain of $C$. acetobutylicum displayed growth on xylan plates (data not shown). This result is in concordance with the literature [39] and demonstrated that the inability of our wild-type strain to grow on xylan as a sole carbon source is not solely a result of the loss of one of the native xylanases.

To further investigate the ability of our strains to grow on xylan, we carried out open batch cultures of $5 \%$ beechwood xylan in liquid medium. The strains were precultured in xylose, as this has been demonstrated to enable wild-type $C$. acetobutylicum ATCC 824 to grow on xylan [39], thus allowing a fairer comparison of the solvent profiles of the control and enzyme-producing strains. Under these conditions, all the strains were able to grow using the xylan as a sole carbon source (Fig. 7). Supernatant samples were then analysed via gas chromatography (GC). When grown on xylan, all the analysed strains produced organic acids as the major products, with roughly $60 \mathrm{mM}$ butyric acid and $50 \mathrm{mM}$ acetic acid present at the end of the fermentations. No significant re-assimilation of the acids could be observed and, accordingly, acetone production was very low. Butanol production in the negative control strain CEL07 was also low, with an average production of $9.2 \mathrm{mM}(0.82 \mathrm{~g} / \mathrm{L})$ after $164 \mathrm{~h}$. This result could be expected based on the literature; similar results have been observed for other solventogenic strains when grown on xylan as a sole carbon source, including C. acetobutylicum ATCC 39236 grown on larchwood or oat spelt xylan [72], Clostridium beijerinckii NCP 260 grown on oat spelt xylan [73], and Clostridium sp. G117 grown on beechwood xylan [74]. Nevertheless, in concordance with the plate growth analysis, the xylanase-expressing strains were able to grow more rapidly, with a faster accumulation of biomass (as estimated by cell pellet protein) and organic acids. Interestingly, the xylanase-expressing strains were also able to produce significantly more butanol, with the best performing strain (CEL16) producing a maximum of $15.4 \mathrm{mM}(1.36 \mathrm{~g} / \mathrm{L})$ after $140 \mathrm{~h}$. Strains CEL16 and CEL19, which produced more butanol, also showed a corresponding decline in the rate of butyrate production, 


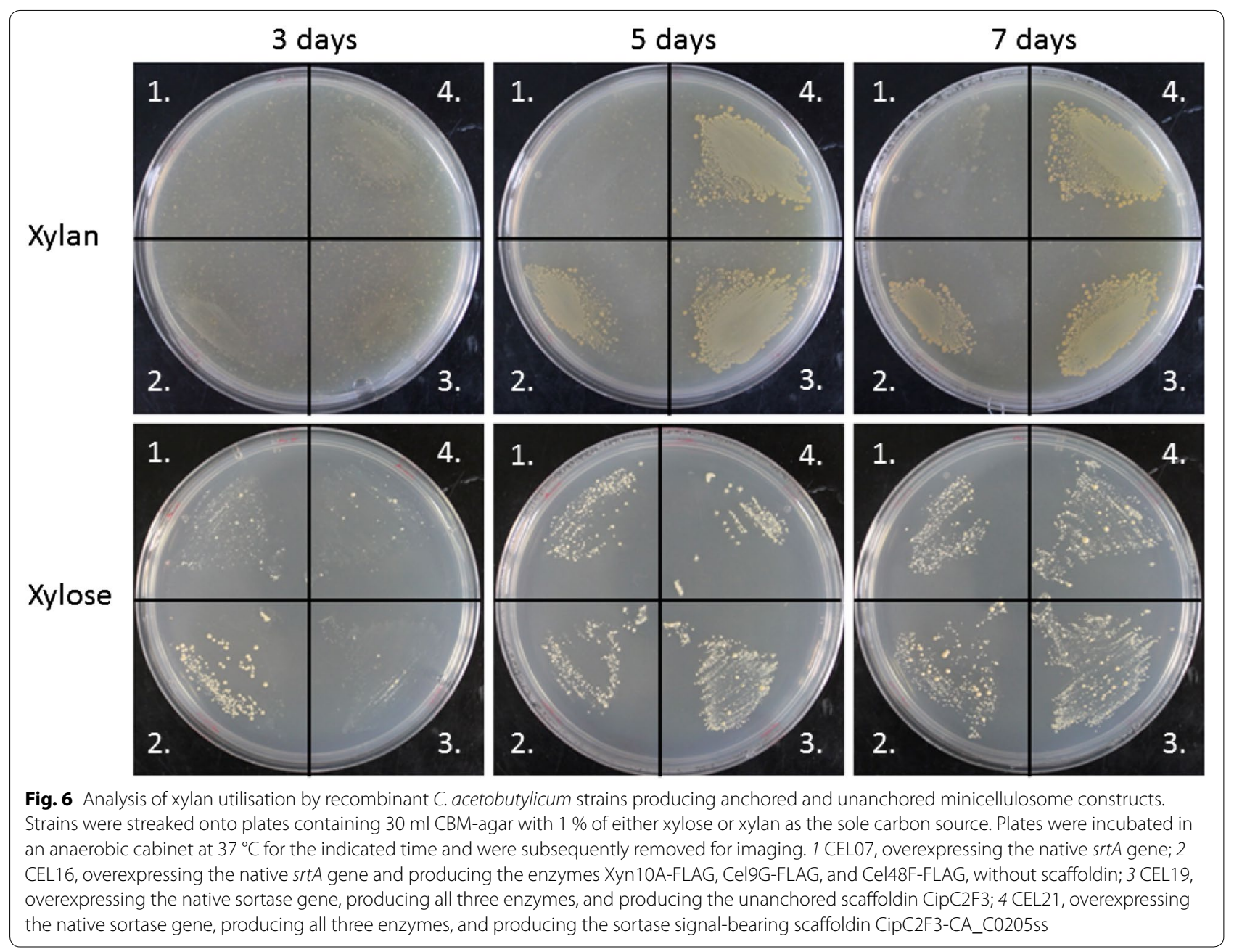

relative to the control, after the onset of butanol production; this is likely to be a result of butyrate re-assimilation. Acetone production in these strains was also slightly higher, correlating with butanol production. However, ethanol could not be accurately assayed, due to the addition of antibiotics dissolved in ethanol to the culture, low detection ability through our GC method, and (presumably) a low level of production. Solvent production in these strains appeared to cease after 116-140 h, corresponding with a decrease in overall pellet protein, possibly as a result of organic acid accumulation or exhaustion of readily hydrolysable substrate. One possible explanation for the increased production of butanol in the xylanase-expressing strains could be a greater proportion of released xylose monomers or shorter xylo-oligosaccharides; when Clostridium sp. G117 was grown on xylose, greater amounts of solvents were produced than when xylo-oligosaccharides were fermented, with xylan giving the lowest levels of solvents and the highest level of butyrate [74]. This may also explain the lower production of butanol by strain CEL21, expressing a cell wallanchored cellulosome; xylo-oligosaccharides released by wall-anchored Xyn10A would be more likely to be taken up by the cell, whereas in other strains, they may remain in the supernatant and undergo further digestion.

Although we were unable to observe growth on lignocellulosic substrates, we decided to carry out sugar release assays to examine the potential of the strains to hydrolyse different substrates. Supernatants were obtained from the strains, concentrated 10-fold, and incubated in the presence of xylan, CMC, PASC, ballmilled wheat straw, and Avicel. After $2 \mathrm{~h}$ (xylan, CMC), or $72 \mathrm{~h}$ (PASC, wheat straw, Avicel), the concentrations of released reducing sugars were analysed by DNS (3,5-dinitrosalicylic acid) assay (Fig. 8). While no difference was observed on CMC, significant increases in reducing sugars were observed when xylan, PASC, or wheat straw was used as the substrate. The greatest difference was observed when xylan was used as the substrate, although it is important to note that glucose was 

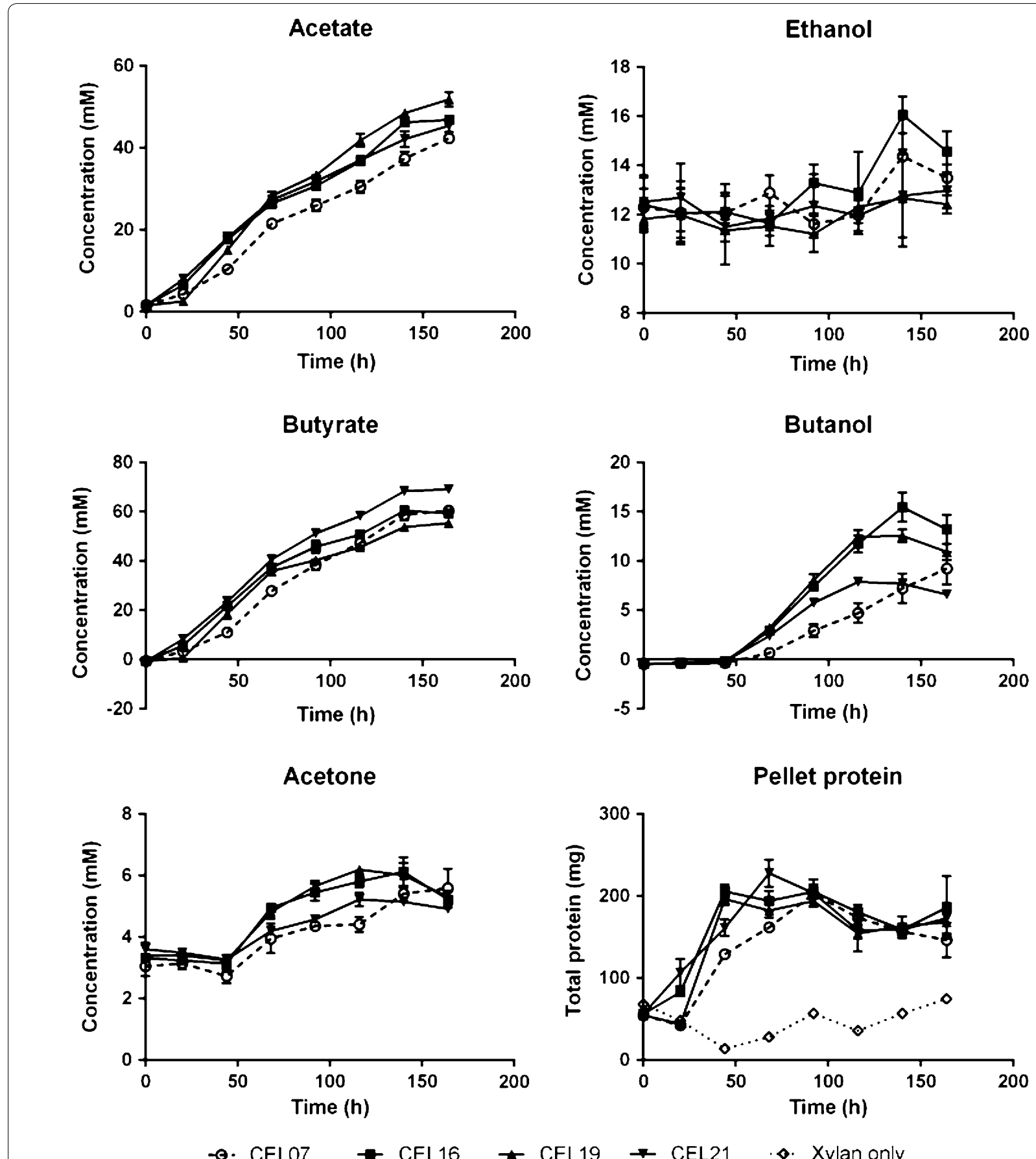

Fig. 7 Product profiles of batch fermentations of $5 \%$ beechwood xylan by recombinant C. acetobutylicum strains. Strains analysed include: CEL07, overexpressing the native srtA gene; CEL16, producing Xyn10A, Cel9G and Cel48F and overexpressing the native srtA gene; CEL19, producing the three hydrolases and the unanchored $\mathrm{CipC} 2 \mathrm{~F} 3$ scaffoldin and overexpressing the native srtA gene; and CEL21, producing the three hydrolases and the wall-anchored scaffoldin CipC2F3-CA_C0205ss and overexpressing the native srtA gene. Results represent the average of three batch cultures; error bars represent standard deviation. The data obtained from the fermentation have been provided in Additional file 3

used as the carbon source for growth, which has been demonstrated to reduce native xylanase expression [39]. However, this allowed us to assess more easily the contribution of Xyn10A to xylan degradation. The most effective strain for xylan degradation was CEL16. This could be expected as complex formation should not assist 

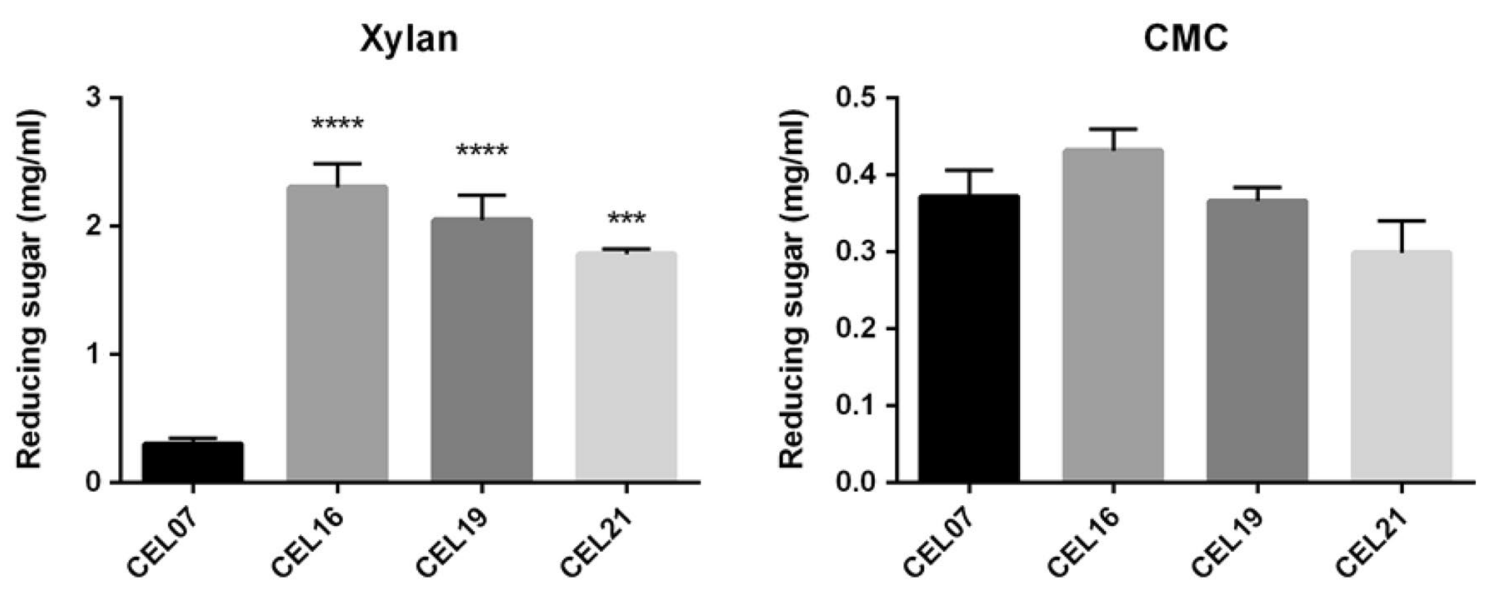

PASC
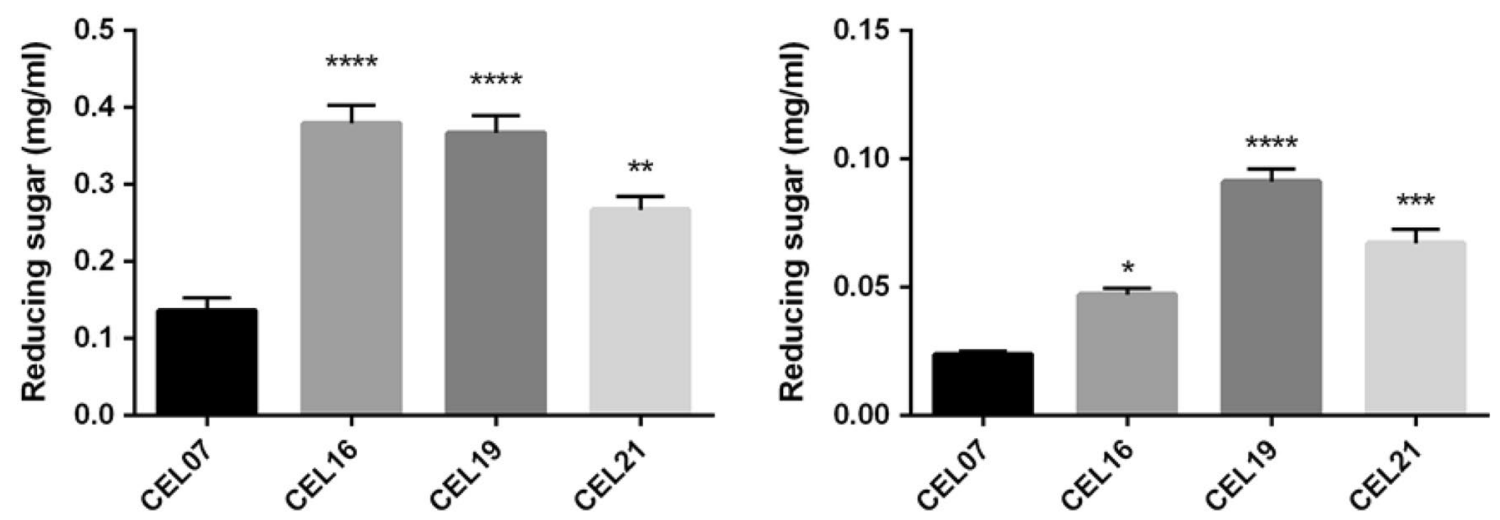

Fig. 8 Release of reducing sugar from beechwood xylan, CMC, PASC and wheat straw by 10-fold concentrated supernatants from recombinant strains of $C$. acetobutylicum. Supernatants were collected from recombinant strains of $C$. acetobutylicum and concentrated 10-fold; concentrated supernatants were incubated with $1 \%$ substrate and the released sugars analysed by DNS assay. The following strains were analysed: CEL07, overexpressing the native srtA gene; CEL16, producing Xyn10A, Cel9G and Cel48F and overexpressing the native srtA gene; CEL19, producing the three hydrolases and the unanchored $\mathrm{CipC} 2 \mathrm{~F} 3$ scaffoldin and overexpressing the native srtA gene; and CEL21, producing the three hydrolases and the wall-anchored scaffoldin CipC2F3-CA_C0205ss and overexpressing the native srtA gene. Differences between levels of released sugars were measured by 1-way ANOVA. Results represent the average of three technical replicates, with the DNS assay also carried out in triplicate; error bars represent standard error of the mean. Hydrolysis reactions were carried out for $2 \mathrm{~h}$ for xylan and CMC and $72 \mathrm{~h}$ for PASC and wheat straw. Significantly more reducing sugar was released from xylan by strains CEL16 and CEL19 $\left(P \leq 0.0001,{ }^{* * * *}\right)$ and by CEL21 $\left(P \leq 0.001\right.$, $\left.{ }^{* * *}\right)$ when compared to CEL07. For CMC, there were no statistical differences between any of the strains. For PASC, there was a significant difference in released reducing sugar between CEL07 and the strains CEL15 and CEL19 $\left(P \leq 0.001,{ }^{* * *}\right)$ and between CEL07 and CEL21 $\left(P \leq 0.01,{ }^{* *}\right)$; there was also a significant difference $(P \leq 0.05)$ between CEL21 and strains CEL16 and CEL19. For wheat straw, there was a significant difference $\left(P \leq 0.05,{ }^{*}\right)$ between CEL07 and CEL16, between CEL07 and CEL19 $\left(P \leq 0.0001,{ }^{* * *}\right)$ and between CEL07 and CEL21 $\left(P \leq 0.001,{ }^{* * *}\right)$; there were also significant differences between CEL16 and CEL19 $(P \leq 0.001)$, CEL16 and CEL21 $(P \leq 0.05)$, and CEL19 and CEL21 $(P \leq 0.05)$. The data obtained from the sugar release assay have been provided in Additional file 3

with xylan degradation; the CBM of CipC would not be able to recognise this substrate. Conversely, supernatants from strain CEL19 had a much greater effect on wheat straw, where CBM binding would be expected. Due to the high expression of xylanase, it may be possible that the sugar released from wheat straw is mostly xylose; however, this cannot explain the significant increases seen for PASC when the hydrolase-expressing strains were used, which would be the result of either Cel9G or Cel48F activity [30,32]. While the formation of a cellulosome did not increase the degradation of PASC, this has been observed previously with chimeric cellulosomes based on Cel9G and Cel48F [34]. CEL21 supernatants appear to have a slightly lower activity against all substrates, which is likely to be a result of the anchoring of a portion of the cellulosomes to the cell. The lack of improvement 
of activity on CMC is more difficult to explain, as Cel9G should be expected to hydrolyse this substrate efficiently [32]. However, C. acetobutylicum has a significant native activity against $\mathrm{CMC}$ [75], which may be obscuring any activity from Cel9G under these conditions. When Avicel was used as the substrate, no sugar release was detectable for any of the supernatants (data not shown), reflecting the extreme recalcitrance of this highly crystalline substrate.

To determine whether the co-production of a cell wallanchored scaffoldin with Xyn10A, Cel9G and Cel48F would allow a significant amount of hydrolase activity to be anchored to the cell, we carried out an additional sugar release assay on ball-milled wheat straw using azide-treated cells from strains CEL21 and CEL19, expressing cell wall-anchored and unanchored minicellulosomes, respectively (Fig. 9). Azide-killed cells were washed to remove unanchored cellulosomes, incubated in a suspension with ball-milled wheat straw over the course of $96 \mathrm{~h}$, and the concentration of reducing sugars in the supernatants was assayed. We were able to detect a significant increase in released reducing sugars when

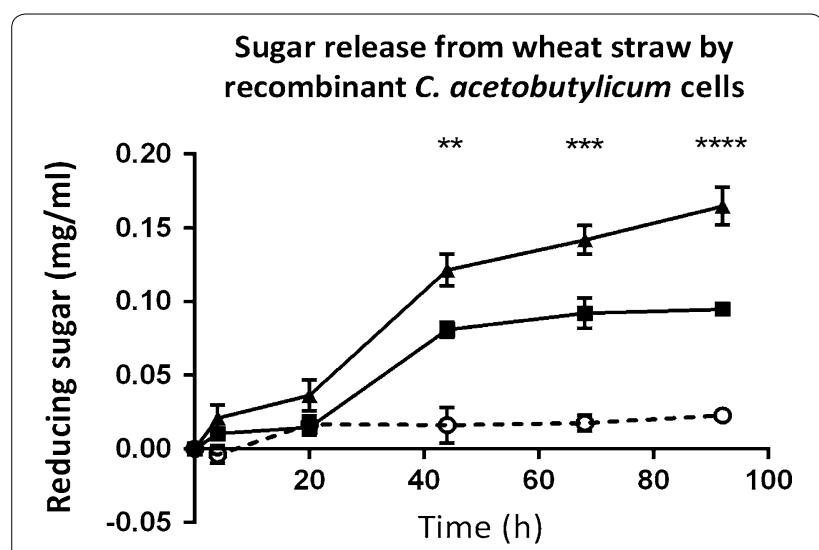

Fig. 9 Sugar release from ball-milled wheat straw by killed cells. Washed, azide-treated cells were incubated in a suspension with $1 \%$ $(\mathrm{w} / \mathrm{v})$ ball-milled wheat straw. Samples were taken at 4, 20, 44, 68, and $92 \mathrm{~h}$ and the concentrations of reducing sugars were analysed by DNS assay. Black triangles, CEL21, overexpressing the native srtA gene and producing a cellulosome consisting of Xyn10A-FLAG, Cel9G-FLAG, Cel48F-FLAG and the anchored scaffoldin CipC2F3-CA C0205ss; black squares, CEL19, overexpressing the native srtA gene and producing a cellulosome with all three enzymes and the unanchored scaffoldin CipC2F3; open circles, wheat straw only. Results represent the average of three technical replicates with error bars representing standard error of the mean. Positive control was carried out using $100 \mu \mathrm{l}$ commercial cellulase from T. reesei (Sigma-Aldrich) and gave a final reducing sugar concentration of $1.71 \mathrm{mg} / \mathrm{ml}$ reducing sugar at $92 \mathrm{~h}$ (omitted for clarity). Difference between the two $C$. acetobutylicum strains is significant to $P \leq 0.01$ at $44 \mathrm{~h}\left({ }^{* *}\right), P \leq 0.001$ at $68 \mathrm{~h}\left({ }^{* *}\right)$, and $P \leq 0.0001$ at $92 \mathrm{~h}\left({ }^{* *}\right)$. Results were analysed using GraphPad Prism software. The data obtained from the sugar release assay have been provided in Additional file 3 the cell wall-anchored cellulosomes were expressed, as opposed to the unanchored equivalents, demonstrating the presence of functional cellulosomes on the cell surface.

This successful production of a cell wall-anchored cellulosome opens several potential avenues by which activity could be increased. Firstly, the composition of the enzymes could be further optimised; it could be possible to introduce a fourth enzyme, such as Cel9E, which is a major component of C. cellulolyticum cellulosomes [31] and has a strong synergy with Cel9G [34], or Cel9U, which is the most active of the C. cellulolyticum GH9 enzymes [33]. The use of chimeric scaffoldins and enzymes [34] could allow the generation of cellulosomes with specific compositions. Alternatively, discovery and characterisation of a greater range of promoters for use in C. acetobutylicum may allow an increase in the production of the various cellulosome components. Secondly, the level of cell wall attachment could be further increased. Western analysis of supernatant from strain CEL08, producing CipC2F3-CA_C0205ss and overexpressing the native sortase, demonstrates that a significant amount of scaffoldin is lost to the supernatant. Correspondingly, a significant amount of cellulase activity is lost as well, as observed from the reducing sugar and western analyses (Additional file 2: Figures S2, S3) of supernatants from strain CEL21. At present, the modified scaffoldins simply contain the sortase signal grafted to the $\mathrm{C}$-terminus of the protein; the sortase signal may be more efficient in its original context, and the attachment of the $\mathrm{C}$-terminal region of the original substrate may allow greater cell wall anchoring. Another possibility may be the introduction of a secondary cell wall-anchored scaffoldin at a lower level of expression. If the current high level of expression of CipC is still overwhelming the sortase system, then a secondary scaffoldin could be expressed at a lower level; a greater proportion of this scaffoldin would be bound to the cell, which would improve the ratio of anchored to unanchored minicellulosomes.

The low level of production of Cel48F is likely to be one of the main limitations in our strategy. GH48 enzymes play a crucial role in cellulolysis [76], and are generally amongst the most prevalent $\mathrm{GH}$ enzymes found in cellulosomes [24, 77-80]. However, C. acetobutylicum appears to be unable to produce large quantities of this class of enzyme; attempts at overexpressing the C. cellulolyticum GH48, and even the native enzyme, from plasmids have had limited success [27]. Correspondingly, in our recombinant strains, Cel $48 \mathrm{~F}$ is produced at a lower level than any of the other components despite the use of the strongest available promoter. To determine whether Cel48F was forming inclusion bodies or becoming trapped in the cell membrane, 
we carried out a cell fractionation on strain CEL12, expressing only Cel48F-Flag from the $\mathrm{P}_{\text {facoid }}$ promoter (Additional file 3: Figure S4). However, we were unable to detect the presence of Cel48F-Flag in any of the cellular fractions analysed. This result is in concordance with the work of Mingardon et al. [27], where Cel48F produced by recombinant $C$. acetobutylicum was detectable in the supernatant, but not in cell lysates. Alternative explanations for the poor production of Cel48F could include instability of the mRNA or degradation of the protein. Purified Cel48F has been observed to degrade, losing the dockerin domain, even when stored at $4{ }^{\circ} \mathrm{C}$ [30]; as our Cel48F protein bears a FLAG tag at the $\mathrm{C}$-terminus, the loss of the dockerin would result in a protein undetectable by our anti-FLAG antibody. Addressing the level of GH48 production is likely to be the greatest obstacle towards generating a CBP strain of C. acetobutylicum.

The improved ability of the Xyn10A-expressing strains to grow on xylan as a sole carbon source is a particularly interesting outcome. Hemicelluloses are a major component of cellulosic biomass and are a side-product of certain lignocellulose pretreatments [81, 82]. As such, they are a potential feedstock for biofuel production. A recent study has considered the possibility of using C. acetobutylicum to ferment the hemicellulose fraction of pretreated lignocellulose into acetone-butanol [81]. However, this required the dilute acid hydrolysis of the xylan, an additional pretreatment step which was observed to produce inhibitory compounds which negatively impacted the fermentation profile. Although C. acetobutylicum ATCC 824 is able to grow on xylan in liquid culture when precultured with xylose, it is not able to grow after serial cultures with xylan as a sole carbon source [39]; this may be a regulatory issue, as a mutant that was able to continually grow on xylan could be isolated. On solid medium, it is possible that Xyn10A is able to release enough xylose to induce the production of the native xylanases, or that Xyn10A is able to complement the native xylanases and thus provide increased xylan degradation. It should be considered that while many solventogenic clostridia are able to grow on xylan as a sole carbon source, the products of fermentation are typically organic acids, and there is little or no solvent production [72-74]. However, in liquid culture, our Xyn10A-expressing strains were able to grow faster and produce butanol at up to twice the rate of the control strain. The idea that this significant improvement could be provided by the activity of a single enzyme hints at the possibility of engineering $C$. acetobutylicum for CBP of hemicellulose, an interesting avenue for further study.

\section{Conclusions}

The generation of an organism suitable for CBP of lignocellulose is an important goal for synthetic biology, promising a more sustainable and cost-effective pathway for production of biofuels and other chemicals. In this work, we have been able to accomplish several key milestones for the development of $C$. acetobutylicum as a potential CBP chassis.

Through the use of ACE technology, we have been able to stably integrate into the genome and express genes encoding a variety of GH enzymes and a scaffoldin protein, allowing the in vivo production of recombinant minicellulosomes. This has built upon our previous work by increasing the number and range of activities of the produced hydrolases, as well as by optimising the expression levels of the genes by the use of a range of promoters. However, C. acetobutylicum is only able to produce small amounts of the important cellobiohydrolase Cel48F, reflecting previously observed issues with the expression of this enzyme class [27, 29]. The difficulty of production of the GH48 enzymes is likely to be the main barrier to the use of C. acetobutylicum in CBP.

Anchoring of the cellulosome to the cell wall has been suggested to be important for growth on lignocellulose, and we have been able to achieve this through the use of the native $C$. acetobutylicum sortase system. To our knowledge, this is the first demonstration of the activity of $C$. acetobutylicum SrtA and the first demonstration of cell surface display of a heterologous protein in this organism. Although a significant amount of scaffoldin remains in the supernatant, there are several potential routes for increasing the efficiency of anchoring, such as by the fusion of a longer $\mathrm{C}$-terminal sequence from the native sortase substrate, or by the optimisation of the ion content of the growth medium [83]. With further optimisation, this ability to display proteins on the cell surface of $C$. acetobutylicum may have a number of other potential applications.

We have demonstrated the formation of minicellulosomes in vivo by our recombinant strains. Furthermore, by combining cellulase production with expression of a sortase-anchored scaffoldin, we have been able to generate a strain capable of producing a cell wall-anchored minicellulosome. Although the strains are still unable to grow on lignocellulose, significant increases in released reducing sugar from xylan, PASC and wheat straw can be observed when incubated with supernatants from our recombinant strains, and from wheat straw when incubated with cells producing a cell wall-anchored minicellulosome. Additionally, expression of Xyn10A appears to enable $C$. acetobutylicum to grow on solid medium with xylan as a sole carbon source, and to produce increased 
amounts of butanol when grown on xylan in liquid culture. This is a significant improvement over the wild type and may suggest that engineering of $C$. acetobutylicum for CBP of xylan could be a valid goal for future work.

In conclusion, while we were unable to generate a strain capable of growth on lignocellulose, we feel that our work provides a valuable proof of concept for development of C. acetobutylicum for CBP, and demonstrates the potential for future engineering of this organism.

\section{Methods}

For a full list of plasmids, strains and oligonucleotides used in this study, see Tables S1, S2 and S3 (Additional file 5). For the sequences of the proteins and genetic components used in this study, see Additional file 6.

\section{Construct assembly}

Plasmid construction was carried out using Fermentas FastDigest restriction enzymes and Promega T4 DNA ligase (M1804) in accordance with the manufacturer's instructions. PCR was carried out using Thermo-Fisher Phusion DNA polymerase (F-530S). E. coli Top10 was routinely used as the cloning host. In this section, bolded numbers in curved brackets refer to the relevant row in Table S1.

\section{Vectors}

As the promoters used in this study contained the lac operator, it was necessary to introduce the $l a c I^{Q}$ gene to the vectors to repress the promoters. The construction of the vectors pMTL_JH16_lacIQ (68) and pJ201_lacIQ (27) has been previously described [29]. The lacI ${ }^{Q}$ gene was excised from pMTL-JH16_lacIQ via PmeI digest and introduced to the pMTL-JH14 (75) and pMTL-JH12 (82) [42] vectors by blunt-end ligation after linearising with the same enzyme, generating the pMTL-JH14 lacIQ (76) and pMTL-JH12_lacIQ (83) vectors. The $\mathrm{P}_{\text {fac } \mathrm{OID}}$ promoter of pMTL82254_facOid_CatP (77) was introduced to the pMTL-JH14_lacIQ vector by NotI/NheI cloning, generating the pMTL-JH14_lacIQ facOID (78) vector.

To carry out iterative ACE assembly, the long homology arm of the pMTL-JH14lac vector was replaced with a sequence comprising the first $\sim 1500 \mathrm{bp}$ of BB2fdxOID_Cel9G, amplified from pJ201_lacIQ_BB2fdxOID_Cel9G_FLAG (56) using the 9G_arm_fd and 9G_arm_rev primers and cloned into the NheI/AscI sites of pMTL-JH14_lacIQ, creating the pBW1 (85) vector.

\section{Terminator constructs}

All terminator sequences were synthesised as complementary pairs of single-stranded BB2-format oligonucleotides, were annealed to form double stranded DNA, and were cloned into the pJ201_lacIQ vector (29-35). A BB2-format CipA2-FLAG construct was available from the PJ201_CipA2_FLAG (28) vector used in our previous work [29]. BB2 cloning was used to insert CipA2 downstream of the terminator sequences, producing terminator-CipA2 constructs (36-42). These were ligated into the NotI/NheI sites of pMTL-JH16 (60), generating integration vectors (61-67), which were subsequently integrated into the thl locus of C. acetobutylicum.

\section{Enzymes}

Plasmids containing C. cellulolyticum Cel9G, Cel48F, and Xyn10A (43, 44 and 45) were provided by Dr. Katrin Schwarz. A FLAG tag sequence was introduced at the C-terminus by BB2 cloning, either by adding a FLAG tag derived from annealed oligonucleotides, or by ligating into the pJ201_FLAG_2xStop vector (12), generating pJ202_Cel9G_FLAG (46), pJ201_Cel48F_FLAG (47), and pJ202_Xyn10A_FLAG (48). As these genes had been designed with an NdeI restriction site overlapping the start codon, the promoter could be changed via this restriction site. The NdeI/NheI fragments of pJ202 Cel9G_FLAG and pJ201_Cel48F_FLAG were ligated into the NdeI/NheI-digested pMTL-JH14_lacIQ_facOID vector, generating the pMTL-JH14_lacIQ_facOID_Cel9G (79) and pMTL-JH14_lacIQ_facOID_Cel48F (80) vectors, which were subsequently integrated at the $p y r E$ locus of $C$. acetobutylicum pyrE $E^{-}$, generating the CEL11 and CEL12 strains. The $\mathrm{P}_{\mathrm{BB} 2 t h l \mathrm{OID}}, \mathrm{P}_{\mathrm{BB} 2 f d x \mathrm{OID}}$, and $\mathrm{P}_{\mathrm{BB} 2 f a-}$ cOID promoters were synthesised as BB2-format fragments $(5,6,7)$, lacking the RBS and 18 bp upstream, and were integrated in front of a BB2-format catP gene [pJ201 lacIQ_CatP (49)] bearing an RBS and immediate $12 \mathrm{bp}$ upstream region from the $C$. acetobutylicum thl gene. BB2 assembly thus restored the full length of the promoter, with the 6 bp BB2 scar replacing the missing 6 bp $(\mathbf{5 0}, \mathbf{5 1}, \mathbf{5 2})$; activity of the promoters was confirmed by resistance to chloramphenicol in E. coli. Xyn10A_FLAG, Cel9G_FLAG and Cel48F_FLAG were placed under the control of these promoters by integrating the NdeI/NheIdigested enzyme constructs into the pJ201_RBS_CatP vector, generating pJ201_lacIQ_BB2facOID_Xyn10A_ FLAG (53), pJ201_lacIQ_BB2thlOID_Xyn10A FLAG (54), pJ201_lacIQ_BB2fdxOID_Cel9G_FLAG (56) and pJ201_lacIQ_BB2facOID_Cel48F_FLAG (57). BB2facOID_Xyn10A_FLAG was inserted into the NotI/NheI sites of pMTL-JH14_lacIQ, generating pMTL-JH14_lacIQ_BB2facOid_Xyn10A_FLAG (81), which was integrated into the genome of C. acetobutylicum. To assemble the three-enzyme gene cassette, BB2fdxOID_Cel9G_FLAG was cloned upstream of the EcoT1 terminator via $\mathrm{BB} 2$ cloning, producing pJ201_lacIQ_BB2fdxOid_Cel9G_FLAG_EcoT1 
This construct was subsequently inserted upstream of pJ201_lacIQ_BB2facOid_Cel48F_FLAG via BB2 cloning, generating pJ201_lacIQ_BB2fdxOID_Cel9G_FLAG_ EcoT1_BB2FacOID_Cel48F_FLAG (59); this construct was cloned into pMTL_JH12_lacIQ via the NotI/NheI restriction sites, generating PMTL-JH12_lacIQ_GF (84). This vector was used to integrate the BB2fdxOID_Cel9G and BB2facOID_Cel48F genes at the pyrE locus of $C$. acetobutylicum, generating CEL14. Similarly, the BB2th1Oid_Xyn10A_FLAG construct was cloned upstream of the TtyrS terminator, generating pJ201_lacIQ_BB2th1Oid_Xyn10A_FLAG_TtyrS (55). BB2thlOID_Xyn10A_ TtyrS was cloned into the $\mathrm{pBW} 1$ vector using the NotI/ NheI sites, generating pBW1_ BB2facOID_Xyn10AFLAG_TtyrS (86), which was integrated at the pyrE site of CEL14, creating the CEL15 strain.

\section{CipC miniscaffoldin variants}

CipC3 was assembled from three BB2-format fragments synthesised by Biomatik, the first encoding the native RBS, CBD, X domain, and first cohesin of C. cellulolyticum CipC [PBMH_CBD_X_C1 (1)], the second encoding the second cohesin [PBMH_C2 (2)], and the third encoding the third cohesin [pBMH_C3 (3)]. Iterative $\mathrm{BB} 2$ cloning was used to assemble the three fragments and introduce a FLAG tag at the C-terminus. This process generated the intermediate constructs pJ201_ CipC_CBD_X_C1_C2 (14) and pJ202_CipC_CBD_X C1_C2_C3 (15). Additionally, a 'scarless' variant, pBMH_ScarlessCipC (4), was synthesised as a single BB2 fragment. Both CipC3 variants were FLAG-tagged by BB2 cloning, generating PJ201_BBCipC3_FLAG (16) and pJ202_ScarlessCipC3_FLAG (17).

In previous work, an N-terminally FLAG-tagged $\mathrm{CipC} 3$ variant (NCipC) had been assembled; sortase signals (CA_C0353ss and CA_C0205ss) were synthesised as BB2-format fragments (8 and 9) and integrated at the $\mathrm{C}$-terminus through $\mathrm{BB} 2$ cloning, generating pBMH_NCipC_CA_C0353ss (18) and pBMH_NCipC CA_C0205ss (19). pJ204_NCipC_stop (20) was assembled by BB2 cloning into pJ204_2xStop (13). Internally FLAG-tagged variants were subsequently assembled through PCR of these variants with the primers C2F3FD and C2F3_BMHrev (for constructs in pBMH) or C2F3_204rev (for constructs in pJ204), followed by BB2-format assembly of the PCR products and CipC_ CBD_X_C1_C2. This generated the pJ201_CipC2F3 CA_C0353ss (21), pJ201_CipC2F3_CA_C0205ss (22), and pJ201_CipC2F3_stop (23) constructs.

All CipC3 variants were cloned into the pMTL-JH16 ACE integration vector (generating 69, 70, 71, 72, and 73) and integrated into the thl locus of C. acetobutylicum.

\section{Sortases}

$S$. aureus $\operatorname{srtA}$ was amplified using the primers SrtA start_fd and SrtA_nostop_rev. This yielded a $635 \mathrm{bp}$ fragment containing the $s r t A$ gene with no stop codon, a $5^{\prime}$ NdeI restriction site overlapping the start codon, and a $3^{\prime}$ NheI restriction site. An RBS from the C. acetobutylicum thl gene was added using the NdeI site, producing the PJ202_RBS_SaSrtA_nostop (24) vector. The EcoRI/NheI fragment of this vector was ligated into the EcoRI/SpeI-digested pJ204_2xStop vector, producing the pJ204_RBS_SaSrtA_stop (25) vector; the EcoRI/NheI fragment of pJ201_CipC2F3_CA_C0205ss was ligated into the EcoRI/SpeI-digested pJ204_RBS_SrtA_stop vector to generate pJ204_CipC2F3_CA_C0205ss_SaSrtA (26). The NotI/NheI fragment of this vector was ligated into pMTL-JH16 to generate pMTL-JH16_ CipC2F3 CA_C0205ss_SaSrtA (74), allowing integration of the CipC2F3_CA_C0205ss/Sa-SrtA operon into the C. acetobutylicum genome at the thl locus via ACE.

The promoter of the thiolase gene from $C$. perfringens was synthesised by Biomatik as a BB2 fragment with no RBS [pBMH_Tcpf_noRBS (10)] and placed upstream of a BB2-format CatP gene in the same manner as the $\mathrm{P}_{\mathrm{BB} 2 t h l O i d}, \mathrm{P}_{\mathrm{BB} 2 f d x \text { Oid }}$ and $\mathrm{P}_{\mathrm{BB} 2 f a c \text { Oid }}$ promoters described previously. This produced the pJ201_lacIQ Tcpf_CatP vector (87), of which the NotI/NheI fragment was ligated into pMTL82151 (88) producing the pMTL82151_Tcpf_CatP expression vector (89). C. acetobutylicum and $B$. cereus sortase genes were amplified from C. acetobutylicum ATCC 824 and B. cereus ATCC 10987 genomic DNA using the primers CaSrtA_fd/CaSrtA_rev and Bcer_fw/Bcer_rev, respectively. These fragments were treated with $\mathrm{NdeI} / \mathrm{NheI}$ and ligated into the NdeI/NheI-digested pMTL82151_Tcpf_CatP vector, generating pMTL82151_Tcpf_CaSrtA (90) and pMTL82151_Tcpf_BcSrtA (92). L. monocytogenes srtA was amplified from genomic DNA using the primers $\mathrm{Gb}_{-}$ Lm_Fw and Gb_Lm_Rev; the pMTL82151_Tcpf_RBSthl_ CatP backbone was digested with NdeI and NheI, and the pMTL82151_Tcpf_LmSrtA vector (91) was assembled though Gibson assembly using Gibson Assembly ${ }^{\circledR}$ Master Mix (New England Biolabs) in accordance with the manufacturer's protocol.

\section{Culture conditions}

E. coli Top 10 was used for routine cloning and assembly of plasmid constructs. For electroporation of C. acetobutylicum, DNA was methylated by electroporation into and isolation from E. coli pAN-2 [84]. All E. coli strains were cultured in liquid lysogeny broth (LB) medium at $37{ }^{\circ} \mathrm{C}$ with shaking at $200 \mathrm{rpm}$, or on solid LB-agar at $37{ }^{\circ} \mathrm{C}$. However, the cloning of promoter-enzyme and 
promoter-sortase constructs required the strains to be grown at $30^{\circ} \mathrm{C}$ to maintain the stability of the constructs. C. acetobutylicum ATCC 824 and all derived strains were cultured inside a MACS-MG-1000 anaerobic workstation (Don Whitley) with an atmosphere of 80:10:10 (vol:vol:vol) $\mathrm{N}_{2}: \mathrm{H}_{2}: \mathrm{CO}_{2}, 70 \%$ humidity, and a temperature of $37^{\circ} \mathrm{C}$. Strains were routinely cultured on CGMagar [85] and in liquid 2xYTG medium (16 g/l tryptone, $10 \mathrm{~g} / \mathrm{l}$ yeast extract, $4 \mathrm{~g} / \mathrm{l} \mathrm{NaCl}, \mathrm{pH}$ 5.2). Transformation of $C$. acetobutylicum was accomplished by electroporation as described previously [84]. Antibiotic selection was carried out using either thiamphenicol $(15 \mu \mathrm{g} / \mathrm{ml})$ or erythromycin $(50 \mu \mathrm{g} / \mathrm{ml})$ as appropriate. Strains in which the pyrE gene had been truncated were grown in the presence of $20 \mu \mathrm{g} / \mathrm{ml}$ uracil; pyrE mutants were selected on $400 \mu \mathrm{g} / \mathrm{ml}$ fluoroorotic acid and $1 \mu \mathrm{g} / \mathrm{ml}$ uracil.

\section{Expression of cellulosomes for western blot analysis}

C. acetobutylicum strains were cultured for protein expression analysis in 2xYTG medium buffered to $\mathrm{pH} 7$ with $40 \mathrm{mM}$ MOPS as previously described [29]. C. acetobutylicum strains were plated on CGM-agar supplemented with the relevant antibiotics and incubated in the anaerobic cabinet overnight. In the morning, growth from these plates was used to inoculate $5 \mathrm{ml}$ anaerobic 2xYTG pH 5.2; after $4 \mathrm{~h}, 5 \mathrm{ml}$ 2xYTG + $40 \mathrm{mM}$ MOPS $\mathrm{pH} 7$ was added. After a further $4 \mathrm{~h}$ of growth, this culture was used to prepare a series of 10 -fold serial dilutions and incubated in the cabinet overnight.

Overnight cultures in the exponential phase of growth were used to inoculate $30 \mathrm{ml} 2 \mathrm{xYTG}+40 \mathrm{mM}$ MOPS $\mathrm{pH} 7$ to an $\mathrm{OD}_{600}$ of 0.05 ; these cultures were incubated in the anaerobic cabinet until the $\mathrm{OD}_{600}$ had reached approximately 0.8 . At this point, the entire culture was centrifuged at $5000 \mathrm{~g}$ for $10 \mathrm{~min}$ at $4{ }^{\circ} \mathrm{C}$; pellets were discarded, and the supernatants concentrated for western analysis. For SDS-PAGE, $20 \mathrm{ml}$ supernatant samples were concentrated 100 -fold via TCA precipitation as described by Schwarz et al. [86] and resuspended in $2 \times$ loading dye + DTT (1:1 dilution of Thermo-Fisher NuPAGE ${ }^{\circledR}$ LDS Sample Buffer (4X) with $1 \mathrm{M}$ Tris pH 8, with DTT added to a concentration of $0.2 \mathrm{M}$ ). For native PAGE, supernatants were treated by addition of Proteinase Inhibitor Cocktail VII (Calbiochem) at a dilution of 50:1, and concentrated 100-fold using Corning ${ }^{\circledR}$ Spin- $\mathrm{X}^{\circledR}$ UF concentrators $(6 \mathrm{ml}, 10,000 \mathrm{MWCO})$ at $4000 \mathrm{~g}$ in a swing bucket rotor.

\section{SDS-PAGE and western blotting}

For denaturing PAGE, $20 \mu \mathrm{l}$ TCA-precipitated sample in $2 x$ loading dye was loaded onto a polyacrylamide gel (NuPAGE ${ }^{\circledR}$ Novex $^{\circledR} 4-12 \%$ Bis-Tris Protein Gels, $1.0 \mathrm{~mm}$, Thermo-Fisher). Gel electrophoresis was carried out at $120 \mathrm{~V}$ for approximately $2 \mathrm{~h}$ using $1 \mathrm{x}$ MES SDS running buffer (diluted from NuPAGE ${ }^{\circledR}$ MES SDS Running Buffer (20X), Thermo-Fisher).

For native PAGE, $10 \mu \mathrm{l}$ Novex $^{\circledR}$ Tris-Glycine Native Sample Buffer (2X) (Thermo-Fisher) was added to $10 \mu \mathrm{l}$ concentrated supernatant, and $20 \mu \mathrm{l}$ was loaded onto a polyacrylamide gel $\left(\mathrm{NuPAGE}^{\circledR}\right.$ Novex $^{\circledR} 3-8$ \% TrisAcetate Protein Gels, $1.0 \mathrm{~mm}$ ). Gel electrophoresis was carried out at $150 \mathrm{~V}$ for approximately $2 \mathrm{~h}$ using $1 \mathrm{x}$ Trisglycine native running buffer (diluted from Novex ${ }^{\circledR}$ TrisGlycine Native Running Buffer (10X), Thermo-Fisher).

SDS-PAGE gels were stained with Coomassie Blue; gels were washed with water 3 times for $5 \mathrm{~min}$ to remove SDS, and were stained by immersion in staining solution $(0.1 \%$ Coomassie Blue R, 40 \% ethanol, $10 \%$ acetic acid) for $1 \mathrm{~h}$. Gels were then destained by immersion in destaining solution ( $40 \%$ ethanol, $10 \%$ acetic acid).

Western blotting was carried out using BioRad TransBlot $^{\circledR}$ Turbo $^{\mathrm{TM}}$ transfer system and Trans-Blot ${ }^{\circledR}$ Turbo $^{\mathrm{TM}}$ Mini PVDF Transfer Packs in accordance with the manufacturer's protocol, using the pre-programmed 'mixed MW' program (1.3 A, $25 \mathrm{~V}, 7 \mathrm{~min})$. Membranes were blocked by addition of $30 \mathrm{ml}$ blocking buffer, consisting of TBS (Tris-buffered saline; $50 \mathrm{mM}$ Tris, $150 \mathrm{mM}$ $\mathrm{NaCl}, \mathrm{pH} 8)+5 \%$ milk powder (Marvel Original Dried Skimmed Milk Powder), and incubated at room temperature on a shaker at $60 \mathrm{rpm}$ for $1 \mathrm{~h}$. Blocked membranes were labelled by the addition of monoclonal ANTI-FLAG M2-peroxidase antibody (Sigma-Aldrich) at a concentration of $5 \mu \mathrm{l}$ in $30 \mathrm{ml}$ blocking buffer (approx. $0.167 \mathrm{mg}$ / ml) and incubated overnight at $4{ }^{\circ} \mathrm{C}$ on a shaker at $60 \mathrm{rpm}$. Labelled membranes were washed six times with TBS $+0.1 \%$ Tween 20 and stained by the addition of 3 , $3^{\prime}, 5,5^{\prime}$-tetramethylbenzidine.

\section{Cell fractionation}

Fractionation of $C$. acetobutylicum cells was carried out according to the method of Wilcox et al. [87], and modified in accordance with the Clostridium saccharobutylicum NCP 262 protoplasting method described by Allcock et al. [88]. As described above, strains were plated on CGM-agar supplemented with the relevant antibiotics, and incubated at $37^{\circ} \mathrm{C}$ anaerobically for $24 \mathrm{~h}$; a loop of agar was used to inoculate $10 \mathrm{ml}$ reduced 2xYTG, and 10-fold serial dilutions were prepared. Actively growing overnight culture was used to inoculate $10 \mathrm{ml}$ $2 \mathrm{xYTG}+0.4 \%$ glycine to an $\mathrm{OD}_{600}$ of 0.05 . At an $\mathrm{OD}_{600}$ of $0.7-0.9$, cells and supernatant were harvested for fractionation. A volume of culture equivalent to an $\mathrm{OD}_{600}$ of 1 in $1 \mathrm{ml}$ was centrifuged at full speed in a benchtop centrifuge; the supernatant was discarded, and the pellet (the whole cell fraction) stored at $-20{ }^{\circ} \mathrm{C}$. Additionally, a volume of culture equivalent to an $\mathrm{OD}_{600}$ of $5 \mathrm{in} 1 \mathrm{ml}$ 
was centrifuged at $5000 \times g$ for $10 \mathrm{~min}$. A sample of $1 \mathrm{ml}$ supernatant (the supernatant fraction) was retained and concentrated via TCA precipitation to a final volume of $100 \mu \mathrm{l}$, whereas the cell pellet was washed once with $5 \mathrm{ml}$ pre-reduced lysis buffer (TBS with $25 \mathrm{mM} \mathrm{CaCl}_{2}, 25 \mathrm{mM}$ $\mathrm{MgCl}_{2}$, and $0.3 \mathrm{M}$ sucrose) and resuspended in $5 \mathrm{ml}$ of the same buffer supplemented with $3 \mathrm{mg} / \mathrm{ml}$ lysozyme. After $3 \mathrm{~h}$ of incubation in the anaerobic cabinet, $1 \mathrm{ml}$ of the lysozyme-digested cell suspension was removed and centrifuged for $3 \mathrm{~min}$ at $5000 \times g$ in a microcentrifuge prechilled to $4{ }^{\circ} \mathrm{C}$. The supernatant was transferred to a fresh $2 \mathrm{ml}$ microcentrifuge tube and centrifuged at full speed for $20 \mathrm{~min}$. The supernatant from this centrifugation (the cell wall fraction) was concentrated to $100 \mu \mathrm{l}$ via TCA precipitation, while the pellet (the protoplast fraction) was frozen at $-20^{\circ} \mathrm{C}$. The protoplast and whole cell fractions were resuspended in $100 \mu \mathrm{l} 2 \times$ loading dye + DTT, as this was observed to be sufficient for lysis. All fractions were then subjected to SDS-PAGE and western blotting as described above.

\section{Fluorescence microscopy}

Overnight cultures of $C$. acetobutylicum strains were prepared in 2xYTG as previously described and used to inoculate $10 \mathrm{ml}$ of $2 \mathrm{xYTG}$ medium to an $\mathrm{OD}_{600}$ of 0.05 . At an $\mathrm{OD}_{600}$ of $0.8-1.0$, a volume equivalent to $5 \mathrm{ml}$ at an $\mathrm{OD}_{600}$ of 1 was harvested by centrifugation at $7000 \times g$ for $10 \mathrm{~min}$. The resulting pellet was washed twice with $5 \mathrm{ml}$ TBS and fixed with $5 \mathrm{ml} 4 \%$ paraformaldehyde in PBS (Alfa Aesar) for $30 \mathrm{~min}$ at $4{ }^{\circ} \mathrm{C}$. After fixing, cells were washed three times with $5 \mathrm{ml}$ TBS, and then blocked for $1 \mathrm{~h}$ in $5 \mathrm{ml} \mathrm{TBS}+0.1 \%$ sodium azide $+1 \%$ BSA. Cells were stored in this buffer at $4{ }^{\circ} \mathrm{C}$ until required.

Blocked cells were centrifuged and labelled with Monoclonal Anti-FLAG M2 ${ }^{\circledR}$ (mouse) antibody (SigmaAldrich, F1804) at a 1:100 dilution in $1 \mathrm{ml}$ TBS $+1 \%$ BSA. Cells were incubated with this antibody for $1-2 \mathrm{~h}$ at room temperature on a rocker, and washed three times with $1 \mathrm{ml}$ TBS $+0.1 \%$ Tween-20. Cells were then labelled overnight with an anti-mouse Alexa-fluor ${ }^{\circledR} 647$ conjugated (goat) antibody (Cell Signalling, \#4410) at a dilution of 1:1000 in $1 \mathrm{ml}$ TBS $+1 \%$ BSA. The labelled cells were subsequently washed overnight, resuspended in Vectashield hardening mounting medium (Vectorlabs $\mathrm{H}-1400)$ supplemented with $10 \mathrm{mM}$ MEA (Cysteamine Hydrochloride, Sigma M6500-25G), and spotted onto a microscope slide for analysis. After the hardening of the mounting media $(1 \mathrm{~h})$, dSTORM imaging was performed as follows.

Super resolution (dSTORM) microscopy was carried out on a Zeiss Elyra PS.1 microscope equipped with Zen 2012 acquisition and processing software and fitted with an Objective alpha Plan-Apochromat $100 \times / 1.46$ Oil DIC M27 objective lens (Zeiss, 420792-9800-000). Samples were excited using the 642 and $405 \mathrm{~nm}$ laser lines (at 50.0 and $0.0700 \%$ intensity, respectively) and fluorescence was detected using the LP 655 filterset. Imaging frequency was set to $50 \mathrm{~Hz}$ at a camera gain of 200 .

Image processing was carried out in Zen 2012 Black using the PALM module. The 30,000 images were processed where single molecule events were identified with the peak intensity to noise value set to six. Drift correction was applied using model-based automatic, eight segments settings. To avoid oversampling the same molecule, Group filter was set to: max on time 5, off gap 10, capture radius 2, equiv. of $20 \mathrm{~nm}$. Other filters applied: localisation precision 2-40 nm, number of photons $350-$ 5000, PSF width 117-222 nm, background 40-5000.

\section{Plate growth assay}

All strains used in the plate growth assay were cultured overnight on CGM-agar supplemented with the relevant antibiotics. Growth from these plates was used to inoculate CBM agar [89] plates supplemented with $1 \%$ xylose or $1 \%$ beechwood xylan (Sigma-Aldrich, X4252) instead of glucose. Plates were inoculated in triplicate, and single plates were removed from the cabinet for imaging at 3, 5 and 7 days.

\section{Fermentation of xylan}

For growth on xylan, strains were precultured in $30 \mathrm{ml}$ CBM medium with $0.5 \%$ xylose instead of glucose to facilitate native xylanase production [39]. At an $\mathrm{OD}_{600}$ of $0.2-0.3,5 \mathrm{ml}$ preculture was used to inoculate three $250 \mathrm{ml}$ flasks containing CBM with $5 \%$ beechwood xylan (Sigma-Aldrich, X4252) instead of glucose and with $0.5 \%$ calcium carbonate. An additional flask was prepared to provide a non-inoculated control. Cultures were incubated in an anaerobic chamber at $37{ }^{\circ} \mathrm{C}$, and $1 \mathrm{ml}$ samples were taken at $0,20,44,68,92,116,140$, and $164 \mathrm{~h}$ after inoculation. Samples were centrifuged at full speed in a bench-top centrifuge for $3 \mathrm{~min}$ at $4{ }^{\circ} \mathrm{C}$, and the supernatants and pellets were frozen.

\section{Solvent analysis via gas chromatography}

A stock solution was prepared, containing $1 \mathrm{M}$ acetone, $1 \mathrm{M}$ ethanol, $1 \mathrm{M}$ butanol, $1 \mathrm{M}$ butyric acid and $1 \mathrm{M}$ acetic acid. The stock solution was subsequently diluted to give a range of standards from 1 to $150 \mathrm{mM}$. ELGA water was used to provide a negative control. For each standard and supernatant sample, $500 \mu \mathrm{l}$ was transferred to a microcentrifuge tube and acidified by addition of $5 \mu \mathrm{l}$ of $10 \mathrm{M}$ sulphuric acid. $500 \mu \mathrm{l}$ propyl propionate with $50 \mathrm{mM}$ valeric acid was added to each 
tube; tubes were vortexed, centrifuged in a bench-top centrifuge for $1 \mathrm{~min}$, and $300 \mu \mathrm{l}$ of the organic phase transferred to a glass sample vial. Solvent concentrations were analysed using GC (Thermo Scientific FOCUS GC) fitted with a Thermo Scientific Trace TR FFAP column $(30 \mathrm{~m} \times 0.25 \mathrm{~mm} \times 0.25 \mu \mathrm{m})$. A volume of $1 \mu \mathrm{l}$ was injected into the column using a split/splitless injector at $240{ }^{\circ} \mathrm{C}$, with a split ratio of $50: 1$ and a split flow of $50 \mathrm{ml} / \mathrm{min}$. Initial oven temperature was $50{ }^{\circ} \mathrm{C}$, maintained for $1 \mathrm{~min}$, before increasing by $40{ }^{\circ} \mathrm{C} /$ min to $210{ }^{\circ} \mathrm{C}$, and holding at $210{ }^{\circ} \mathrm{C}$ for $1 \mathrm{~min}$; hydrogen was used as the carrier gas, with a constant column flow rate of $0.8 \mathrm{ml} / \mathrm{min}$. Solvents were detected with a flame ionisation detector operated at $270{ }^{\circ} \mathrm{C}$. Data were analysed using Microsoft Excel and GraphPad Prism software.

\section{Protein analysis of cell pellets}

Frozen cell pellets were resuspended in $250 \mu \mathrm{l}$ PBS and allowed to autolyse for $150 \mathrm{~min}$ at room temperature. Suspensions were centrifuged at full speed for $1 \mathrm{~min}$ and the supernatants transferred to fresh microcentrifuge tubes. Protein concentrations were analysed by Sigma-Aldrich Bicinchoninic Acid Protein Assay Kit (BCA1) according to the manufacturer's instructions, using 96-well plates. Samples were measured in triplicate and concentrations determined by comparison to a BSA standard curve.

\section{Sugar release assay using concentrated supernatants}

Relevant strains were grown in triplicate to an OD of 1.0 in CBM medium containing $40 \mathrm{mM}$ MOPS pH 6.8, $0.5 \%$ glucose, and supplemented with $15 \mu \mathrm{g} / \mathrm{ml}$ thiamphenicol. The supernatant was collected by centrifugation at $5000 \mathrm{~g}$ for $10 \mathrm{~min}$ at $4{ }^{\circ} \mathrm{C}$. The supernatant was subsequently concentrated 10 times using Corning Spin-X UF $20 \mathrm{ml}$ 10 K MWCO columns (Sigma-Aldrich, 431488) using a swing bucket rotor at $4000 \mathrm{~g}$ at $4{ }^{\circ} \mathrm{C}$. Residual sugars were subsequently removed using the Spin-X UF columns by three rounds of dialfiltration using $10 \mathrm{ml}$ of $100 \mathrm{mM}$ Tris- $\mathrm{HCl}, 1 \mathrm{mM} \mathrm{CaCl} 2, \mathrm{pH}$ 6.0.

The concentrated supernatants were incubated at $37^{\circ} \mathrm{C}$ in a $1: 1$ ratio with a $2 \%$ solution of substrate in $100 \mathrm{mM}$ Tris- $\mathrm{HCl}, 1 \mathrm{mM} \mathrm{CaCl}, \mathrm{pH} 6.0$, giving a final substrate concentration of $1 \%$. The following substrates were tested: sodium carboxymethyl cellulose (Sigma-Aldrich, 419303), beechwood xylan (Sigma-Aldrich, X4252), Avicel PH-101 (Fluka Biochemicals, 11366), PASC (prepared from Avicel PH-101 using the method described by Zhang et al. [90]), and ball-milled wheat straw. In accordance with the protocol described by King et al. [91], reactions with xylan and CMC were incubated for $2 \mathrm{~h}$, whereas reactions with Avicel, PASC and wheat straw were incubated for $72 \mathrm{~h}$. Samples were then analysed via DNS assay; Avicel, PASC and wheat straw samples were centrifuged at $10,000 \mathrm{~g}$ for $1 \mathrm{~min}$ prior to analysis.

\section{Sugar release assay using killed cells}

A stock suspension of $10 \%$ ball-milled wheat straw in $\mathrm{dH}_{2} \mathrm{O}$ was prepared and sterilised by autoclavation. Sample tubes were prepared by the addition of $1 \mathrm{ml}$ wheat straw suspension to $4 \mathrm{ml}$ assay buffer $(20 \mathrm{mM}$ Tris-acetate, $\mathrm{pH}$ 6.0, $1 \mathrm{mM} \mathrm{CaCl}_{2}, 0.1 \%$ sodium azide).

Serially diluted overnight cultures of $C$. acetobutylicum strains were prepared in $2 \mathrm{xYTG}+40 \mathrm{mM}$ MOPS $\mathrm{pH} 7$ as described in "Expression of cellulosomes for western blot analysis" section, except that the overnight cultures were grown in a volume of $30 \mathrm{ml}$. After overnight incubation, cultures with an $\mathrm{OD}_{600}$ of $0.8-1.0$ were used to inoculate flasks containing $300 \mathrm{ml} 2 \mathrm{xYTG}+40 \mathrm{mM}$ MOPS $\mathrm{pH}$ 7 to an $\mathrm{OD}_{600}$ of 0.05 . These cultures were grown to an $\mathrm{OD}_{600}$ of 0.8-1.0. At this point, a volume with an $\mathrm{OD}_{600}$ equivalent to an $\mathrm{OD}_{600}$ of 1 in $40 \mathrm{ml}$ was centrifuged, and the cells washed once in $40 \mathrm{ml}$ assay buffer before being resuspended in $40 \mathrm{ml}$ assay buffer.

Sample tubes were treated by addition of $5 \mathrm{ml}$ cell suspension and incubated at $37^{\circ} \mathrm{C}$ with shaking at $200 \mathrm{rpm}$. Each condition was prepared in triplicate. A positive control was carried out by the addition of $100 \mu \mathrm{l}$ Trichoderma reesei cellulase preparation (Sigma-Aldrich, C2730) to tubes containing $10 \mathrm{ml}$ assay buffer with $1 \%$ wheat straw. Samples were taken at 0,12, 20, 44, 68 and $92 \mathrm{~h}$, centrifuged, and the supernatants retained for analysis.

\section{Analysis of reducing sugars via DNS assay}

Concentrations of reducing sugars were analysed by dinitrosalicylic acid (DNS) assay as described by King et al. [91]. Supernatant samples $(60 \mu \mathrm{l})$ were mixed with $120 \mu \mathrm{l}$ DNS reaction mixture (1\% dinitrosalicylic acid, $0.2 \%$ phenol, $0.05 \%$ sodium sulphite, $1 \%$ sodium hydroxide, $10 \%$ sodium potassium tartrate) and heated at $95{ }^{\circ} \mathrm{C}$ for $5 \mathrm{~min}$ in a 96-well PCR plate. The reaction was immediately quenched by cooling to $4{ }^{\circ} \mathrm{C}$. Of this reaction mix-

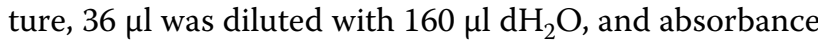
at $540 \mathrm{~nm}$ measured using a TECAN plate reader, with the exception of powdered wheat straw, where $100 \mu \mathrm{l}$ reaction mix was measured without dilution, and compared to an equivalent calibration curve. All samples were measured in triplicate and results were expressed as an average of three means; measurements were normalised against the relevant blank and calibrated by comparison to glucose. Statistical analyses were carried out using GraphPad Prism software to calculate standard error of the mean (SEM) and statistical significance. 


\section{Additional files}

Additional file 1. Analysis of terminator strengths in C. acetobutylicum ATCC 824. This file contains Figure S1, comprising the western blot analysis of efficiencies of a range of Rho-independent terminators in $C$. acetobutylicum.

Additional file 2. SDS-PAGE/western blot of supernatants for sugar release assays. This file contains Figure S2 and Figure S3, comprising the SDS-PAGE/western blot and Coomassie stain analysis of the supernatants used in the sugar release assay shown in Fig. 8.

Additional file 3. Fractionation of strains expressing Cel48F-Flag and Xyn10A-Flag. This file contains Figure S4, comprising the western blot analysis of cell fractions of strains expressing Cel48F-Flag and Xyn10A-Flag.

Additional file 4. Fermentation and sugar release assay data. This file contains the raw data from the xylan fermentation represented in Fig. 7 and the sugar release assays represented in Figs. 8 and 9.

Additional file 5. Plasmids, strains, and oligonucleotides used in the study. This file contains Table S1, Table S2 and Table S3, containing a full list of vectors used in this study, the details of the E. coli and C. acetobutylicum strains used in this study, and a full list of all oligonucleotides, respectively.

Additional file 6. Sequences of the proteins and genetic components used in the study. This file contains the amino acid sequences of the proteins used in this study, as well as the nucleotide sequences of the promoters and terminators used in the construction of the XGF gene cassette and sortase expression vectors.

\section{Abbreviations}

ABE: acetone-butanol-ethanol; ACE: allele-coupled exchange; BB2: BioBrick 2; BCA: bicinchoninic acid; CBM: clostridial basal medium/carbohydrate binding module; CBP: consolidated bioprocessing; CGM: clostridial growth medium; DNS: 3,5-dinitrosalicylic acid; GC: gas chromatography; PASC: phosphoric acidswollen cellulose; PBS: phosphate-buffered saline; SEM: standard error of the mean; TBS: tris-buffered saline; TCA: trichloroacetic acid.

\section{Authors' contributions}

BJW carried out the strain construction, western analyses, cell growth assays, xylan fermentation, and protein concentration analysis, analysed the data, and drafted the manuscript. KK assembled the sortase expression constructs, carried out and analysed the killed cell sugar release activity assay, prepared the samples for fluorescence microscopy, prepared the supernatant samples for GC analysis, and helped to design the study and draft the manuscript. TWS carried out and analysed the concentrated supernatant sugar release assays and revised the manuscript. RM carried out and analysed the fluorescence microscopy study and revised the manuscript. KW helped design and coordinate the study and helped to revise the manuscript. NPM designed and co-ordinated the study and helped to revise the manuscript. All authors read and approved the final manuscript.

\section{Author details}

${ }^{1}$ Clostridia Research Group, BBSRC/EPSRC Synthetic Biology Research Centre, School of Life Sciences, University of Nottingham, Nottingham NG7 2RD, UK. ${ }^{2}$ SLIM Imaging Unit, Faculty of Medicine and Health Sciences, School of Life Sciences, University of Nottingham, Nottingham NG7 2RD, UK.

\section{Acknowledgements}

The authors would like to thank Dr. Katrin Schwarz for providing the Cel9G, Cel48F, and Xyn10A constructs, Dr. Ying Zhang for providing the $P_{\text {facoID }}$ promoter, and Dr. Phil Hill for the gift of L. monocytogenes EGD and B. cereus ATCC 10987 genomic DNA. We would also like to thank James Fothergill and Jonathan Humphreys for assistance with the GC analysis. The project was funded by the UK Biotechnology and Biological Sciences Research Council (BBSRC) (Grant no. BB/G016224/1) as part of the BBSRC Sustainable Bioenergy Centre (BSBEC). Super resolution microscopy was funded by the BBSRC (Grant no. BB/L013827/1) and run by the School of Life Sciences Imaging (SLIM) at the University of Nottingham.

\section{Competing interests}

The authors declare that they have no competing interests.

Received: 4 December 2015 Accepted: 10 May 2016

Published online: 23 May 2016

\section{References}

1. Rajagopal D, Sexton SE, Roland-Holst D, Zilberman D. Challenge of biofuel: filling the tank without emptying the stomach? Environ Res Lett. 2007;2(4):044004

2. Naik S, Goud WV, Rout PK, Dalai AK. Production of first and second generation biofuels: a comprehensive review. Renew Sust Energ Rev. 2010;14(2):578-97.

3. Zhao X, Zhang L, Liu D. Biomass recalcitrance. Part I: the chemical compositions and physical structures affecting the enzymatic hydrolysis of lignocellulose. Biofuel Bioprod Bior. 2012;6(4):465-82. doi:10.1002/ bbb.1331.

4. Scheller HV, Ulvskov P. Hemicelluloses. Annu Rev Plant Biol. 2010;61(1):263-89. doi:10.1146/annurev-arplant-042809-112315.

5. Vanholme R, Demedts B, Morreel K, Ralph J, Boerjan W. Lignin biosynthesis and structure. Plant Physiol. 2010;153(3):895-905.

6. Hadar Y. Sources for lignocellulosic raw materials for the production of ethanol. Lignocellulose conversion. Berlin: Springer; 2013. p. 21-38.

7. Chaturvedi V, Verma P. An overview of key pretreatment processes employed for bioconversion of lignocellulosic biomass into biofuels and value added products. 3 Biotech. 2013;3(5):415-31. doi:10.1007/ s13205-013-0167-8.

8. Olson DG, McBride JE, Joe Shaw A, Lynd LR. Recent progress in consolidated bioprocessing. Curr Opin Biotechnol. 2012;23(3):396-405. doi:10.1016/j.copbio.2011.11.026.

9. Akinosho $\mathrm{H}$, Yee K, Close D, Ragauskas A. The emergence of Clostridium thermocellum as a high utility candidate for consolidated bioprocessing applications. Front Chem. 2014;2:66. doi:10.3389/fchem.2014.00066.

10. Yutin N, Galperin MY. A genomic update on clostridial phylogeny: gramnegative spore-formers and other misplaced clostridia. Environ Microbiol. 2013;15(10):2631-41. doi:10.1111/1462-2920.12173.

11. Yang $X, X u$ M, Yang S-T. Metabolic and process engineering of Clostridium cellulovorans for biofuel production from cellulose. Metab Eng. 2015;32:39-48. doi:10.1016/j.ymben.2015.09.001.

12. Fan $L H$, Zhang ZJ, Yu XY, Xue YX, Tan TW. Self-surface assembly of cellulosomes with two miniscaffoldins on Saccharomyces cerevisiae for cellulosic ethanol production. Proc Natl Acad Sci USA. 2012:109(33):13260-5. doi:10.1073/pnas.1209856109.

13. Lilly M, Fierobe H-P, Van Zyl WH, Volschenk H. Heterologous expression of a Clostridium minicellulosome in Saccharomyces cerevisiae. FEMS Yeast Res. 2009:9(8):1236-49. doi:10.1111/j.1567-1364.2009.00564.x.

14. Anderson TD, Miller Jl, Fierobe H-P, Clubb RT. Recombinant Bacillus subtilis that grows on untreated plant biomass. Appl Environ Microbiol. 2013;79(3):867-76. doi:10.1128/aem.02433-12.

15. Nölling J, Breton G, Omelchenko MV, Makarova KS, Zeng Q, Gibson R, et al. Genome sequence and comparative analysis of the solvent-producing bacterium Clostridium acetobutylicum. J Bacteriol. 2001;183(16):482338. doi:10.1128/jb.183.16.4823-4838.2001.

16. Collins M, Lawson P, Willems A, Cordoba J, Fernandez-Garayzabal J, Garcia P, et al. The phylogeny of the genus Clostridium: proposal of five new genera and eleven new species combinations. Int J Syst Bacteriol. 1994:44(4):812-26.

17. Jones DT, Woods DR. Acetone-butanol fermentation revisited. Microbiol Rev. 1986;50(4):484-524.

18. Swana J, Yang Y, Behnam M, Thompson R. An analysis of net energy production and feedstock availability for biobutanol and bioethanol. Bioresour Technol. 2011;102(2):2112-7. doi:10.1016/j.biortech.2010.08.051.

19. Raganati F, Olivieri G, Götz P, Marzocchella A, Salatino P. Butanol production from hexoses and pentoses by fermentation of Clostridium acetobutylicum. Anaerobe. 2015;34:146-55. doi:10.1016/j.anaerobe.2015.05.008.

20. Lynd LR, Weimer PJ, van ZyI WH, Pretorius IS. Microbial cellulose utilization: fundamentals and biotechnology. Microbiol Mol Biol Rev. 2002;66(3):506-77. doi:10.1128/mmbr.66.3.506-577.2002. 
21. Fontes CMGA, Gilbert HJ. Cellulosomes: highly efficient nanomachines designed to deconstruct plant cell wall complex carbohydrates. Annu Rev Biochem. 2010;79(1):655-81. doi:10.1146/ annurev-biochem-091208-085603.

22. Shoham Y, Lamed R, Bayer EA. The cellulosome concept as an efficient microbial strategy for the degradation of insoluble polysaccharides. Trends Microbiol. 1999;7(7):275-81. doi:10.1016/S0966-842X(99)01533-4.

23. Maki M, Leung KT, Qin W. The prospects of cellulase-producing bacteria for the bioconversion of lignocellulosic biomass. Int J Biol Sci. 2009;5(5):500-16.

24. Sabathé F, Bélaïch A, Soucaille P. Characterization of the cellulolytic complex (cellulosome) of Clostridium acetobutylicum. FEMS Microbiol Lett. 2002;217(1):15-22. doi:10.1111/j.1574-6968.2002.tb11450.x.

25. Sabathé F, Soucaille P. Characterization of the CipA scaffolding protein and in vivo production of a minicellulosome in Clostridium acetobutylicum. J Bacteriol. 2003;185(3):1092-6. doi:10.1128/ jb.185.3.1092-1096.2003.

26. Mingardon F, Perret S, Bélaïch A, Tardif C, Bélaïch JP, Fierobe HP. Heterologous production, assembly, and secretion of a Minicellulosome by Clostridium acetobutylicum ATCC 824. Appl Environ Microbiol. 2005;71(3):1215-22. doi:10.1128/aem.71.3.1215-1222.2005.

27. Mingardon F, Chanal A, Tardif C, Fierobe H-P. The issue of secretion in heterologous expression of Clostridium cellulolyticum cellulase-encoding genes in Clostridium acetobutylicum ATCC 824. Appl Environ Microbiol. 2011;77(9):2831-8. doi:10.1128/aem.03012-10.

28. Kim AY, Attwood GT, Holt SM, White BA, Blaschek HP. Heterologous expression of endo-beta-1,4-D-glucanase from Clostridium cellulovorans in Clostridium acetobutylicum ATCC 824 following transformation of the engB gene. Appl Environ Microbiol. 1994;60(1):337-40.

29. Kovács K, Willson BJ, Schwarz K, Heap JT, Jackson A, Bolam DN, et al. Secretion and assembly of functional mini-cellulosomes from synthetic chromosomal operons in Clostridium acetobutylicum ATCC 824. Biotechnol Biofuels. 2013;6(1):117

30. Reverbel-Leroy C, Pages S, Belaich A, Belaich JP, Tardif C. The processive endocellulase CelF, a major component of the Clostridium cellulolyticum cellulosome: purification and characterization of the recombinant form. J Bacteriol. 1997;179(1):46-52.

31. Fendri I, Tardif C, Fierobe HP, Lignon S, Valette O, Pagès $S$, et al. The cellulosomes from Clostridium cellulolyticum. FEBS J. 2009;276(11):3076-86. doi:10.1111/j.1742-4658.2009.07025.x.

32. Gal L, Gaudin C, Belaich A, Pages S, Tardif C, Belaich JP. CelG from Clostridium cellulolyticum: a multidomain endoglucanase acting efficiently on crystalline cellulose. J Bacteriol. 1997;179(21):6595-601.

33. Ravachol J, Borne R, Tardif C, de Philip P, Fierobe H-P. Characterization of all family-9 glycoside hydrolases synthesized by the cellulosome-producing bacterium Clostridium cellulolyticum. J Biol Chem. 2014;289(11):733548. doi:10.1074/jbc.M113.545046.

34. Fierobe H-P, Bayer EA, Tardif C, Czjzek M, Mechaly A, Bélaïch A, et al. Degradation of cellulose substrates by cellulosome chimeras: substrate targeting versus proximity of enzyme components. J Biol Chem. 2002;277(51):49621-30. doi:10.1074/jbc.M207672200.

35. Li Y, Irwin DC, Wilson DB. Processivity, substrate binding, and mechanism of cellulose hydrolysis by Thermobifida fusca Cel9A. Appl Environ Microbiol. 2007;73(10):3165-72. doi:10.1128/aem.02960-06.

36. Mandelman D, Belaich A, Belaich JP, Aghajari N, Driguez H, Haser R. $\mathrm{X}$-ray crystal structure of the multidomain endoglucanase Cel9G from Clostridium cellulolyticum complexed with natural and synthetic cello-oligosaccharides. J Bacteriol. 2003;185(14):4127-35. doi:10.1128/ jb.185.14.4127-4135.2003.

37. Murashima K, Kosugi A, Doi RH. Synergistic effects of cellulosomal xylanase and cellulases from Clostridium cellulovorans on plant cell wall degradation. J Bacteriol. 2003;185(5):1518-24. doi:10.1128/ JB.185.5.1518-1524.2003.

38. Lee SF, Forsberg CW, Rattray JB. Purification and characterization of two endoxylanases from Clostridium acetobutylicum ATCC 824. Appl Environ Microbiol. 1987:53(4):644-50.

39. Lee SF, Forsberg CW, Gibbins LN. Xylanolytic activity of Clostridium acetobutylicum. Appl Environ Microbiol. 1985;50(4):1068-76.

40. Blouzard JC, Bourgeois C, de Philip P, Valette O, Bélaïch A, Tardif C, et al. Enzyme diversity of the cellulolytic system produced by Clostridium cellulolyticum explored by two-dimensional analysis: identification of seven genes encoding new dockerin-containing proteins. J Bacteriol. 2007;189(6):2300-9. doi:10.1128/jb.00917-06.

41. Xu C, Huang R, Teng L, Wang D, Hemme CL, Borovok I, et al. Structure and regulation of the cellulose degradome in Clostridium cellulolyticum. Biotechnol Biofuels. 2013;6(1):1-15. doi:10.1186/1754-6834-6-73.

42. Heap JT, Ehsaan M, Cooksley CM, Ng YK, Cartman ST, Winzer K, et al. Integration of DNA into bacterial chromosomes from plasmids without a counter-selection marker. Nucleic Acids Res. 2012;40(8):e59. doi:10.1093/ nar/gkr1321.

43. Registry of standard biological parts. http://www.parts.igem.org/. Accessed 3 Dec 2015.

44. Tan PST, van Alen-Boerrigter IJ, Poolman B, Siezen RJ, de Vos WM, Konings WN. Characterization of the Lactococcus lactis pepN gene encoding an aminopeptidase homologous to mammalian aminopeptidase N. FEBS Lett. 1992;306(1):9-16. doi:10.1016/0014-5793(92)80827-4.

45. Boot HJ, Kolen CP, van Noort JM, Pouwels PH. S-layer protein of Lactobacillus acidophilus ATCC 4356: purification, expression in Escherichia coli, and nucleotide sequence of the corresponding gene. J Bacteriol. 1993;175(19):6089-96.

46. Ní Eidhin D, Ryan AW, Doyle RM, Walsh JB, Kelleher D. Sequence and phylogenetic analysis of the gene for surface layer protein, slpA, from 14 PCR ribotypes of Clostridium difficile. J Med Microbiol. 2006;55(1):69-83. doi:10.1099/jmm.0.46204-0.

47. Barthelemy I, Salas M, Mellado RP. In vivo transcription of bacteriophage phi 29 DNA: transcription termination. J Virol. 1987;61(5):1751-5.

48. Grundy FJ, Moir TR, Haldeman MT, Henkin TM. Sequence requirements for terminators and antiterminators in the T box transcription antitermination system: disparity between conservation and functional requirements. Nucleic Acids Res. 2002;30(7):1646-55.

49. Orosz A, Boros I, Venetianer P. Analysis of the complex transcription termination region of the Escherichia coli rrnB gene. Eur J Biochem. 1991;201(3):653-9. doi:10.1111/j.1432-1033.1991.tb16326.x.

50. Trauth S, Bischofs IB. Ectopic integration vectors for generating fluorescent promoter fusions in Bacillus subtilis with minimal dark noise. PLoS One. 2014;9(5):e98360. doi:10.1371/journal.pone.0098360.

51. Platteeuw C, van Alen-Boerrigter I, van Schalkwijk S, de Vos WM. Foodgrade cloning and expression system for Lactococcus lactis. Appl Environ Microbiol. 1996;62(3):1008-13.

52. Yeh CM, Huang XH, Sue CW. Functional Secretion of a type 1 antifreeze protein analogue by optimization of promoter, signal peptide, prosequence, and terminator in Lactococcus lactis. J Agric Food Chem. 2008;56(18):8442-50. doi:10.1021/jf801580s.

53. Reverbel-Leroy C, Belaich A, Bernadac A, Gaudin C, Belaich J-P, Tardif C. Molecular study and overexpression of the Clostridium cellulolyticum celF cellulase gene in Escherichia coli. Microbiology. 1996;142(4):1013-23. doi:10.1099/00221287-142-4-1013.

54. Dumitrache A, Wolfaardt G, Allen G, Liss SN, Lynd LR. Form and function of Clostridium thermocellum biofilms. Appl Environ Microbiol. 2013:79(1):231-9. doi:10.1128/aem.02563-12.

55. Johnson EA, Reese ET, Demain AL. Inhibition of Clostridium thermocellum cellulase by end products of cellulolysis. J Appl Biochem. 1982;4:64-71.

56. Kosugi A, Murashima K, Tamaru Y, Doi RH. Cell-surface-anchoring role of $\mathrm{N}$-terminal surface layer homology domains of Clostridium cellulovorans EngE. J Bacteriol. 2002;184(4):884-8. doi:10.1128/jb.184.4.884-888.2002.

57. Desvaux M. Clostridium cellulolyticum: model organism of mesophilic cellulolytic clostridia. FEMS Microbiol Rev. 2005;29(4):741-64. doi:10.1016/j. femsre.2004.11.003.

58. Rincon MT, Čepeljnik T, Martin JC, Lamed R, Barak Y, Bayer EA, et al. Unconventional mode of attachment of the Ruminococcus flavefaciens cellulosome to the cell surface. J Bacteriol. 2005;187(22):7569-78. doi:10.1128/jb.187.22.7569-7578.2005.

59. Ben David Y, Dassa B, Borovok I, Lamed R, Koropatkin NM, Martens EC, et al. Ruminococcal cellulosome systems from rumen to human. Environ Microbiol. 2015;17(9):3407-26. doi:10.1111/1462-2920.12868.

60. Spirig T, Weiner EM, Clubb RT. Sortase enzymes in gram-positive bacteria. Mol Microbiol. 2011;82(5):1044-59. doi:10.1111/j.1365-2958.2011.07887.x.

61. Desvaux M, Khan A, Scott-Tucker A, Chaudhuri RR, Pallen MJ, Henderson IR. Genomic analysis of the protein secretion systems in Clostridium acetobutylicum ATCC 824. Biochim Biophys Acta. 2005;1745(2):223-53. doi:10.1016/j.bbamcr.2005.04.006. 
62. Schleifer KH, Kandler O. Peptidoglycan types of bacterial cell walls and their taxonomic implications. Bacteriol Rev. 1972;36(4):407.

63. Clancy KW, Melvin JA, McCafferty DG. Sortase transpeptidases: insights into mechanism, substrate specificity, and inhibition. Pept Sci. 2010;94(4):385-96. doi:10.1002/bip.21472.

64. Frankel BA, Kruger RG, Robinson DE, Kelleher NL, McCafferty DG. Staphylococcus aureus sortase transpeptidase SrtA: insight into the kinetic mechanism and evidence for a reverse protonation catalytic mechanism. Biochemistry. 2005;44(33):11188-200. doi:10.1021/bi050141j.

65. Bierne H, Mazmanian SK, Trost M, Pucciarelli MG, Liu G, Dehoux P, et al. Inactivation of the srtA gene in Listeria monocytogenes inhibits anchoring of surface proteins and affects virulence. Mol Microbiol. 2002;43(4):86981. doi:10.1046/j.1365-2958.2002.02798.x.

66. Gaspar AH, Marraffini LA, Glass EM, DeBord KL, Ton-That H, Schneewind O, Bacillus anthracis sortase A (SrtA) anchors LPXTG motif-containing surface proteins to the cell wall envelope. J Bacteriol. 2005;187(13):4646-55. doi:10.1128/JB.187.13.4646-4655.2005.

67. Dhar G, Faull KF, Schneewind O. Anchor structure of cell wall surface proteins in Listeria monocytogenes. Biochemistry. 2000;39(13):3725-33.

68. Navarre WW, Ton-That H, Faull KF, Schneewind O. Anchor structure of staphylococcal surface proteins: II. $\mathrm{COOH}$-terminal structure of muramidase and amidase-solubilized surface protein. J Biol Chem. 1998;273(44):29135-42. doi:10.1074/jbc.273.44.29135.

69. Schneewind O, Mihaylova-Petkov D, Model P. Cell wall sorting signals in surface proteins of gram-positive bacteria. EMBO J. 1993;12(12):4803-11.

70. Liew PX, Wang CLC, Wong S-L. Functional characterization and localization of a Bacillus subtilis sortase and its substrate and use of this sortase system to covalently anchor a heterologous protein to the $B$. subtilis cell wall for surface display. J Bacteriol. 2012;194(1):161-75. doi:10.1128/ jb.05711-11.

71. Ehsaan M, Kuit W, Zhang Y, Cartman ST, Heap JT, Winzer K, et al. Mutant generation by allelic exchange and genome resequencing of the biobutanol organism Clostridium acetobutylicum ATCC 824. Biotechnol Biofuels. 2016;9(1):1-20. doi:10.1186/s13068-015-0410-0.

72. Lemmel SA, Datta R, Frankiewicz JR. Fermentation of xylan by Clostridium acetobutylicum. Enzyme Microb Technol. 1986;8(4):217-21. doi:10.1016/0141-0229(86)90091-8.

73. Qureshi N, Li XL, Hughes S, Saha BC, Cotta MA. Butanol production from corn fiber xylan using Clostridium acetobutylicum. Biotechnol Prog. 2006:22(3):673-80. doi:10.1021/bp050360w.

74. Yan Y, Basu A, Li T, He J. Direct conversion of xylan to butanol by a wild-type Clostridium species strain G117. Biotechnol Bioeng. 2016: doi:10.1002/bit.25940.

75. Lee SF, Forsberg CW, Gibbins LN. Cellulolytic activity of Clostridium acetobutylicum. Appl Environ Microbiol. 1985;50(2):220-8.

76. Sukharnikov LO, Alahuhta M, Brunecky R, Upadhyay A, Himmel ME, Lunin $\mathrm{W}$, et al. Sequence, structure, and evolution of cellulases in glycoside hydrolase family 48. J Biol Chem. 2012;287(49):41068-77. doi:10.1074/jbc. M112.405720
77. Gold ND, Martin VJJ. Global view of the Clostridium thermocellum cellulosome revealed by quantitative proteomic analysis. J Bacteriol. 2007:189(19):6787-95. doi:10.1128/jb.00882-07.

78. Gal L, Pages S, Gaudin C, Belaich A, Reverbel-Leroy C, Tardif C, et al. Characterization of the cellulolytic complex (cellulosome) produced by Clostridium cellulolyticum. Appl Environ Microbiol. 1997;63(3):903-9.

79. Murashima K, Kosugi A, Doi RH. Determination of subunit composition of Clostridium cellulovorans cellulosomes that degrade plant cell walls. Appl Environ Microbiol. 2002;68(4):1610-5. doi:10.1128/ aem.68.4.1610-1615.2002.

80. Artzi L, Morag E, Barak Y, Lamed R, Bayer EA. Clostridium clariflavum key cellulosome players are revealed by proteomic analysis. MBio. 2015;6(3):e00411-15. doi:10.1128/mBio.00411-15.

81. Kudahettige-Nilsson RL, Helmerius J, Nilsson RT, Sjöblom M, Hodge DB, Rova U. Biobutanol production by Clostridium acetobutylicum using xylose recovered from birch Kraft black liquor. Bioresour Technol. 2015;176:71-9. doi:10.1016/j.biortech.2014.11.012.

82. Carvalheiro F, Duarte LC, Gírio FM. Hemicellulose biorefineries: a review on biomass pretreatments. J Sci Ind Res. 2008;67(11):849-64.

83. Suryadinata R, Seabrook SA, Adams TE, Nuttall SD, Peat TS. Structural and biochemical analyses of a Clostridium perfringens sortase $D$ transpeptidase. Acta Crystallogr D Biol Crystallogr. 2015:71(7):1505-13.

84. Heap JT, Pennington OJ, Cartman ST, Carter GP, Minton NP. The ClosTron: a universal gene knock-out system for the genus Clostridium. J Microbiol Methods. 2007;70(3):452-64. doi:10.1016/j.mimet.2007.05.021.

85. Hartmanis MGN, Gatenbeck S. Intermediary metabolism in Clostridium acetobutylicum: levels of enzymes involved in the formation of acetate and butyrate. Appl Environ Microbiol. 1984;47(6):1277-83.

86. Schwarz K, Fiedler T, Fischer R-J, Bahl H. A standard operating procedure (SOP) for the preparation of intra- and extracellular proteins of Clostridium acetobutylicum for proteome analysis. J Microbiol Methods. 2007;68(2):396-402. doi:10.1016/j.mimet.2006.09.018

87. Wilcox MH, Williams P, Smith DG, Modun B, Finch RG, Denyer SP. Variation in the expression of cell envelope proteins of coagulase-negative staphylococci cultured under iron-restricted conditions in human peritoneal dialysate. J Gen Microbiol. 1991;137(11):2561-70.

88. Allcock ER, Reid SJ, Jones DT, Woods DR. Clostridium acetobutylicum protoplast formation and regeneration. Appl Environ Microbiol. 1982;43(3):719-21.

89. O'Brien R, Morris J. Oxygen and the growth and metabolism of Clostridium acetobutylicum. J Gen Microbiol. 1971;68(3):307-18.

90. Zhang YHP, Cui J, Lynd LR, Kuang LR. A transition from cellulose swelling to cellulose dissolution by o-phosphoric acid: evidence from enzymatic hydrolysis and supramolecular structure. Biomacromolecules. 2006;7(2):644-8. doi:10.1021/bm050799c.

91. King BC, Donnelly MK, Bergstrom GC, Walker LP, Gibson DM. An optimized microplate assay system for quantitative evaluation of plant cell wall-degrading enzyme activity of fungal culture extracts. Biotechnol Bioeng. 2009;102(4):1033-44. doi:10.1002/bit.22151.

\section{Submit your next manuscript to BioMed Central and we will help you at every step:}

- We accept pre-submission inquiries

- Our selector tool helps you to find the most relevant journal

- We provide round the clock customer support

- Convenient online submission

- Thorough peer review

- Inclusion in PubMed and all major indexing services

- Maximum visibility for your research

Submit your manuscript at www.biomedcentral.com/submit
BioMed Central 